\title{
Uptake and spreading of anthropogenic trace gases in an eddy-permitting model of the Atlantic Ocean
}

\author{
Arne Biastoch, ${ }^{1}$ Christoph Völker, ${ }^{2}$ and Claus W. Böning ${ }^{1}$ \\ Received 12 October 2006; revised 5 April 2007; accepted 2 July 2007; published 20 September 2007.
}

[1] An eddy-permitting circulation model of the Atlantic Ocean was used to study the effect of mesoscale processes on the uptake and spreading of anthropogenic $\mathrm{CO}_{2}$ and CFC-11. A comparison with a coarser-resolution model version shows anthropogenic tracer distributions with qualitatively similar patterns, but much more structure (e.g., stronger longitudinal gradients) in the eddy-permitting model, improving the agreement with observations. The better representation of the formation of water masses such as subpolar-mode water in the eddy-permitting model has an influence on the distribution of anthropogenic $\mathrm{CO}_{2}$ over density classes, but no influence on the total inventory taken up. In the subpolar Atlantic, the air-sea flux of CFC-11 is dominated by deep-water formation, while the air-sea flux of anthropogenic $\mathrm{CO}_{2}$ extends over a larger part of the subpolar gyre and has a clear association with North Atlantic surface currents. An in-depth analysis of the mechanisms shaping this distribution showed that the entrainment of water from below into the mixed layer determines the structure in the subpolar North Atlantic, whereas the temporal correlation between surface heat fluxes and mixed-layer depth is more important in the subtropical gyre. The northward, integrated heat and anthropogenic $\mathrm{CO}_{2}$ transports in midlatitudes are closely correlated on seasonal to interannual timescales. This has implications for using the ongoing monitoring arrays of the thermohaline circulation for estimation of the transport of anthropogenic $\mathrm{CO}_{2}$.

Citation: Biastoch, A., C. Völker, and C. W. Böning (2007), Uptake and spreading of anthropogenic trace gases in an eddypermitting model of the Atlantic Ocean, J. Geophys. Res., 112, C09017, doi:10.1029/2006JC003966.

\section{Introduction}

[2] The ocean is taking up some part of the trace gases that have been released into the atmosphere by human activity, such as carbon dioxide $\left(\mathrm{CO}_{2}\right)$ or chlorofluorocarbons (CFCs) [Sarmiento and Gruber, 2002]. The uptake of $\mathrm{CO}_{2}$, which is on the order of a third of the total anthropogenic emissions, helps to reduce the anthropogenic part of the greenhouse effect. The present uptake is largely dominated by physical mechanisms [e.g., Sarmiento et al., 1992], namely equilibration with the upper ocean and subsequent transport into the deeper ocean with the formation of deep and intermediate waters. In the future, however, feedbacks between changes in climate, biological productivity and the carbon cycle will play an increasing role [Friedlingstein et al., 2003, and references therein].

[3] Because of the dominant role of the North Atlantic for the formation of deep water, it is also the location of the strongest penetration of the anthropogenic signal into the deep ocean interior [Gruber, 1998; Körtzinger et al., 1998; Keir et al., 1998]. However, the processes relevant for the uptake of anthropogenic carbon $\mathrm{C}_{\mathrm{ant}}$ are not fully understood. On the basis of partial pressure measurements of $\mathrm{CO}_{2}$

\footnotetext{
${ }^{1}$ Leibniz-Institut für Meereswissenschaften, Kiel, Germany.

${ }^{2}$ Alfred-Wegener-Institut, Bremerhaven, Germany.
}

Copyright 2007 by the American Geophysical Union. 0148-0227/07/2006JC003966\$09.00 $\left(p \mathrm{CO}_{2}\right)$ it has recently been conjectured that the air-sea $p \mathrm{CO}_{2}$ difference in the subpolar North Atlantic may have been diminishing over the last decades [Omar et al., 2003; Lefèvre et al., 2004; Omar and Olsen, 2006], indicating a decrease in the uptake of anthropogenic carbon. Global carbon models on the other hand suggest that the North Atlantic is a region of exceptionally strong air-sea flux of $\mathrm{C}_{\text {ant }}$ [e.g., Orr et al., 2001], and that the flux is still continuing to increase. The assumption of an increasing air-sea $p \mathrm{CO}_{2}$ difference has also been used in the calculation of $\mathrm{C}_{\mathrm{ant}}$ flux based on the $p \mathrm{CO}_{2}$ climatology by Takahashi et al. [2002].

[4] Both data- and model-based estimates of anthropogenic trace gas uptake and distribution have their specific limitations: in spite of the tremendous increase in the number and quality of carbon system observations during the WOCE era [Wallace, 2001] and from ongoing volunteer observing ship programs, direct calculations of $\mathrm{CO}_{2}$ flux are still hampered by limitations in temporal and spatial data coverage. Separation of the small $\mathrm{C}_{\mathrm{ant}}$ signal from the large natural background in the ocean interior involve a number of assumptions, such as purely isopycnal transport and fixed elemental stoichiometries [e.g., Gruber et al., 1996], that introduce substantial errors [Matsumoto and Gruber, 2005].

[5] Models have other limitations: One of the more important ones is that, because of the required long integration times, global carbon cycle models still mostly lack an explicit representation of the ocean mesoscale dynamics 
Table 1. Summary of Experiments

\begin{tabular}{|c|c|c|c|}
\hline & Resolution & Wind Forcing & Heat Forcing \\
\hline REF & $1 / 3^{\circ}$ & $\begin{array}{l}\text { ECMWF climatology } \\
+ \text { NCEP anomalies }\end{array}$ & $\begin{array}{l}\text { ECMWF climatology } \\
+ \text { NCEP anomalies }\end{array}$ \\
\hline HEAT & $1 / 3^{\circ}$ & ECMWF climatology & $\begin{array}{l}\text { ECMWF climatology } \\
+ \text { NCEP anomalies }\end{array}$ \\
\hline COARSE & $4 / 3^{\circ}$ & $\begin{array}{l}\text { ECMWF climatology } \\
+ \text { NCEP anomalies }\end{array}$ & $\begin{array}{l}\text { ECMWF climatology } \\
+ \text { NCEP anomalies }\end{array}$ \\
\hline
\end{tabular}

with eddies and frontal structures. To describe the largescale implications of these motions, subgrid-scale parametrization are used in the model equations. The Ocean Carbon Model Intercomparison Project OCMIP has demonstrated that there is still a considerable scatter in modelbased estimates of anthropogenic trace gas uptake and spreading [Orr et al., 2001; Dutay et al., 2002; Matsumoto et al., 2004]. The scatter can be traced back to differences in the physical circulation field caused by differing model resolutions and choices of physical parameterizations [Doney et al., 2004]. Interestingly, a realistic representation of one anthropogenic tracer (e.g., bomb radiocarbon) does not necessarily imply a good representation of others (e.g., CFCs) [Matsumoto et al., 2004], so there is not one 'best' model, demonstrating that the implications of the subgridscale characterizations are not yet fully understood.

[6] Besides a critical assessment of model results against available observational data, there is therefore a need for a better understanding of the processes that drive anthropogenic trace gas uptake and spreading in models. The model investigation presented here contributes to that aim by examining anthropogenic tracer uptake and spreading in an eddy-permitting model. The model configuration used here has extensively been used for studying various aspects of the physical circulation and its interannual to decadal variability [Beismann et al., 2002; Getzlaff et al., 2005]; simulations of CFC uptake have been used to critically assess the deep water formation in the subpolar North Atlantic [Böning et al., 2003; Beismann and Redler, 2003]. The model domain is limited to the Atlantic basin only, and we use the perturbation approach by Siegenthaler and Joos [1992] for separating the increase of dissolved inorganic carbon from its preindustrial value. Both approaches introduce errors into the model solution, but the reduced computational cost allows for a better representation of the mesoscale in its influence on water-mass formation processes.

[7] The paper is organized as follows: After a description of the model (section 2) the distribution and inventories of $\mathrm{C}_{\text {ant }}$ are compared to other models and data-based estimates (section 3). In section 4 we make use of the improved representation of physical processes to discuss the relative importance and spatial distribution of processes that are responsible for anthropogenic carbon uptake in the model. In section 5 we discuss how the physical circulation determines the strength and the timescales of the meridional $\mathrm{C}_{\mathrm{ant}}$ transport. In the discussion (section 6) we discuss the relevance of our findings to the open questions about anthropogenic carbon cycling in the Atlantic.

\section{Model}

[8] The models used here form part of the Family of Linked Atlantic Model Experiments (FLAME) [Böning et al., 2003; Beismann and Redler, 2003], a hierarchy of ocean models in the Atlantic Ocean sharing similar configurations but different horizontal resolutions $\left(4 / 3^{\circ}\right.$, $\left.1 / 3^{\circ}, 1 / 12^{\circ}\right)$. The code is a refined version of the Modular Ocean Model (MOM2) [Pacanowski, 1996], a widely used primitive equation model, with additional parameterizations implemented to better simulate the large-scale thermohaline circulation (see below).

[9] The model domain covers the Atlantic from $70^{\circ} \mathrm{S}$ to $70^{\circ} \mathrm{N}$, with open boundaries across the Drake passage and along $30^{\circ} \mathrm{E}$. The $1 / 3^{\circ}$ configuration of the model, which is mainly used here, has an isotropic horizontal resolution of $1 / 3^{\circ} \times 1 / 3^{\circ} \cos \phi$ (where $\phi$ is the geographical latitude) that results in grid sizes of about $20 \mathrm{~km}$ in the subpolar North Atlantic. This resolution resolves the upper part of the mesoscale spectrum, and is therefore called "eddy permitting." In the vertical, the water column is divided into 45 levels with depth ranges from $10 \mathrm{~m}$ at the surface to $250 \mathrm{~m}$ below $2250 \mathrm{~m}$ depth.

[10] Subgrid-scale processes are parameterized by a Gent and McWilliams [1990] approach, using a rotated diffusion operator [Griffies, 1998] to ensure that mixing of tracers occurs primarily along isopycnals. For a better representation of the Nordic Seas overflows, the bottom boundary layer parametrization of Beckmann and Döscher [1997] is used. The wind influence on the mixed layer depth is simulated explicitly by a Kraus and Turner [1967] mixed layer model.

[11] The physical model was started from a mean climatological temperature and salinity field [Boyer and Levitus, 1997] and spun up for 25 years. After that a 100-year run (1900-2001) was performed. During the first 58 years the wind stress and heat-flux forcing during were taken from a ECMWF climatology [Barnier et al., 1995]. For the years 1958-2001 (serving as the reference experiment, REF), anomalies from the NCEP reanalysis data set [Kalnay et al., 1996] relative to the ECMWF climatology were used to vary the surface forcing interannually. The formulation of the heat fluxes follows that of Eden and Willebrand [2001] in their study of the thermohaline circulation variability, allowing for some feedback of the ocean on the net atmospheric fluxes [Han, 1984; Haney, 1971]. For salinity the surface values have been restored to a monthly Levitus climatology using a timescale of 30 days.

[12] In order to help to elucidate the effects of the atmospheric forcing variability a second experiment (HEAT) was performed, where only heat flux anomalies were used in the years 1958-2001, while the ECMWF climatology without interannual variation was retained for the wind stress data. In addition, the reference model is compared to an identical (except for some resolutiondependent parameters) configuration on a non-eddyresolving $4 / 3^{\circ} \times 4 / 3^{\circ} \cos \phi$ grid (COARSE). All experiments are listed in Table 1.

[13] The model uses the perturbation approach for anthropogenic carbon by Siegenthaler and Joos [1992]. This approach is based on the assumption that the global carbon cycle was in steady state in preindustrial times and that the biological pump [Volk and Hoffert, 1985] has so far not been changed by human influence. With these assumptions, $\mathrm{C}_{\mathrm{ant}}$ can be treated as an inert tracer, independent from the natural background of dissolved inorganic carbon. The 


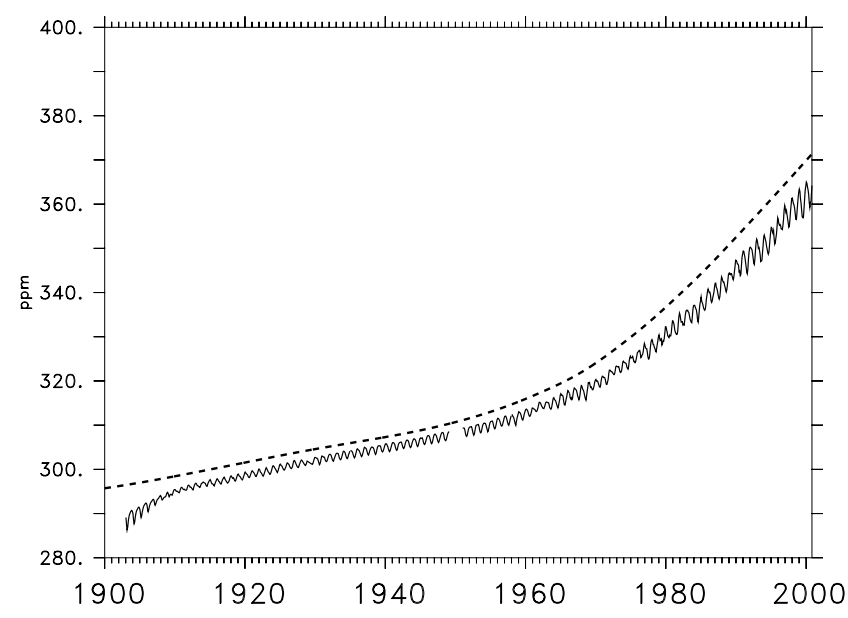

Figure 1. Prescribed atmospheric partial pressure of $\mathrm{CO}_{2}$ (in ppm, dashed line) and modeled surface values (solid line) at BATS station $\left(32^{\circ} \mathrm{N}, 64^{\circ} \mathrm{W}\right)$.

approach allows the model integration period to be limited to the period of major anthropogenic influence. It has successfully been used in several global models [Sarmiento et al., 1992; Caldeira and Duffy, 2000; Orr et al., 2001].

[14] At the surface spatially uniform atmospheric $\mathrm{CO}_{2}$ and $\mathrm{CFC}-11$ partial pressures $\left(p \mathrm{CO}_{2}\right.$ and $\left.p \mathrm{CFC}\right)$ (Figure 1) are prescribed. Atmospheric $p \mathrm{CO}_{2}$ is taken from a combination of ice-core and atmospheric measurements [Enting

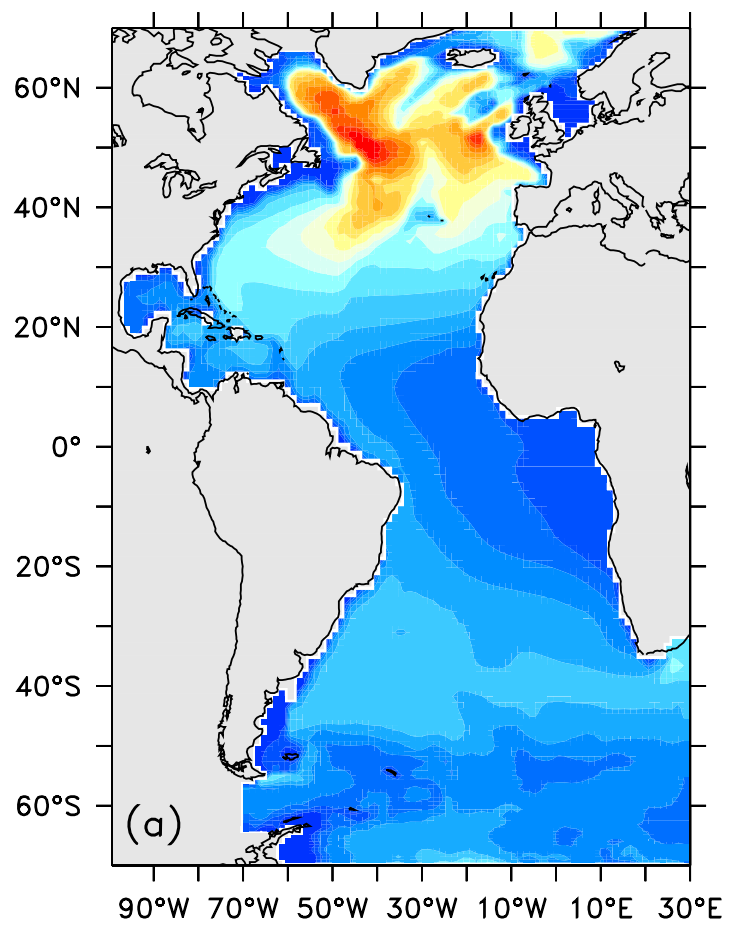

et al., 1994] until 1990, after that the IPCC scenario S650 is used. The $\mathrm{CO}_{2}$ gas exchange is parameterized with a quadratic wind-speed-dependent gas exchange velocity following Wanninkhof [1992]. CFC-11 was initialized (by zero) in year 1958 and integrated similar to $C_{a n t}$ except for different solubility, atmospheric forcing function and gas exchange velocity.

[15] Conditions for $\mathrm{C}_{\mathrm{ant}}$ at the boundaries to adjacent ocean basins were estimated using CFC-11 data. In the Greenland sea, the estimated profile below $750 \mathrm{~m}$ depth by Anderson et al. [2000] was extrapolated assuming equilibrium with the atmosphere at the surface. In the Southern Ocean, we used the $\mathrm{C}_{\text {ant }}$ estimate by Sabine et al. [1999] and the CFC data from Archambeau et al. [1998] to estimate a linear $\mathrm{CFC}-\mathrm{C}_{\mathrm{ant}}$ regression. This linear regression was then used to estimate $\mathrm{C}_{\text {ant }}$ in Drake Passage (using CFC data from Roether et al. [1993]) and in the gap between the Sabine et al. [1999] data and Antarctica at $30^{\circ} \mathrm{E}$ (using CFC data from Archambeau et al. [1998]). The lateral boundary conditions were made time-dependent by scaling them with the atmospheric $p \mathrm{CO}_{2}$ history.

[16] Figure 1 shows the atmospheric (prescribed) and oceanic (model-calculated) $p \mathrm{CO}_{2}$ at the Bermuda Atlantic Time-series Station site in the subtropical Atlantic. The model $p \mathrm{CO}_{2}$ that was initialized in 1900 with no anthropogenic carbon present in the ocean, increases rapidly over the first few years, to catch up with the atmosphere. After that it follows the atmosphere with a lag caused by the finite equilibration time of $\mathrm{CO}_{2}$. The annual cycle in modeled

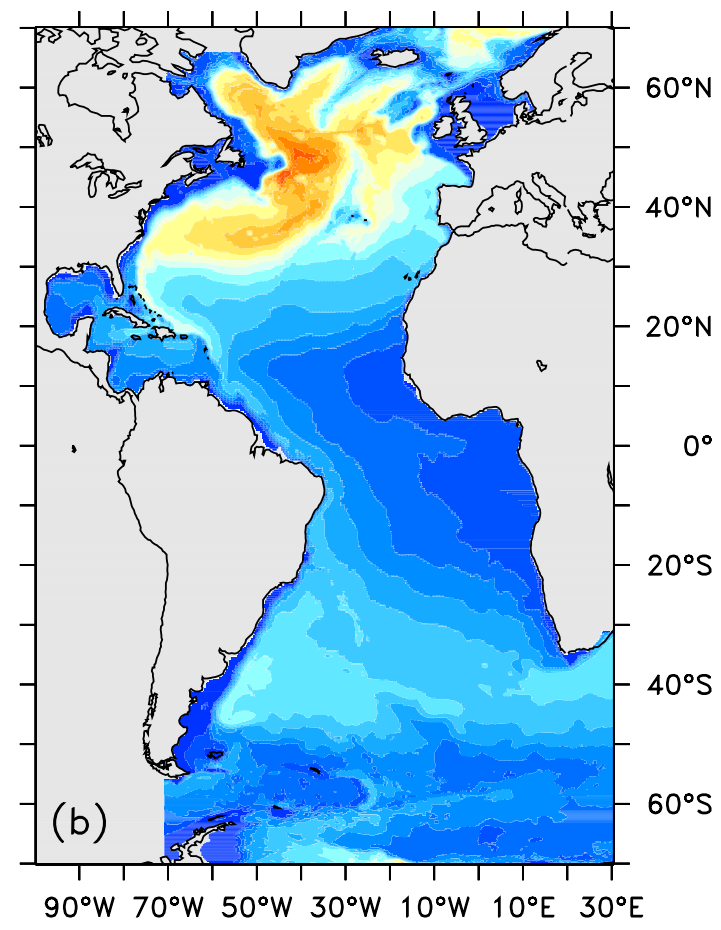

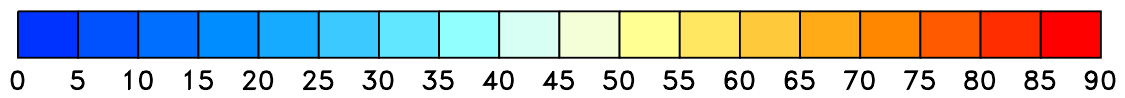

Figure 2. Mean 1990 vertically integrated $C_{\text {ant }}$ inventory (in $\mathrm{mol} \mathrm{m}^{-2}$ ) in the (a) $4 / 3^{\circ}$ (COARSE) and in the (b) $1 / 3^{\circ}$ model (REF). 

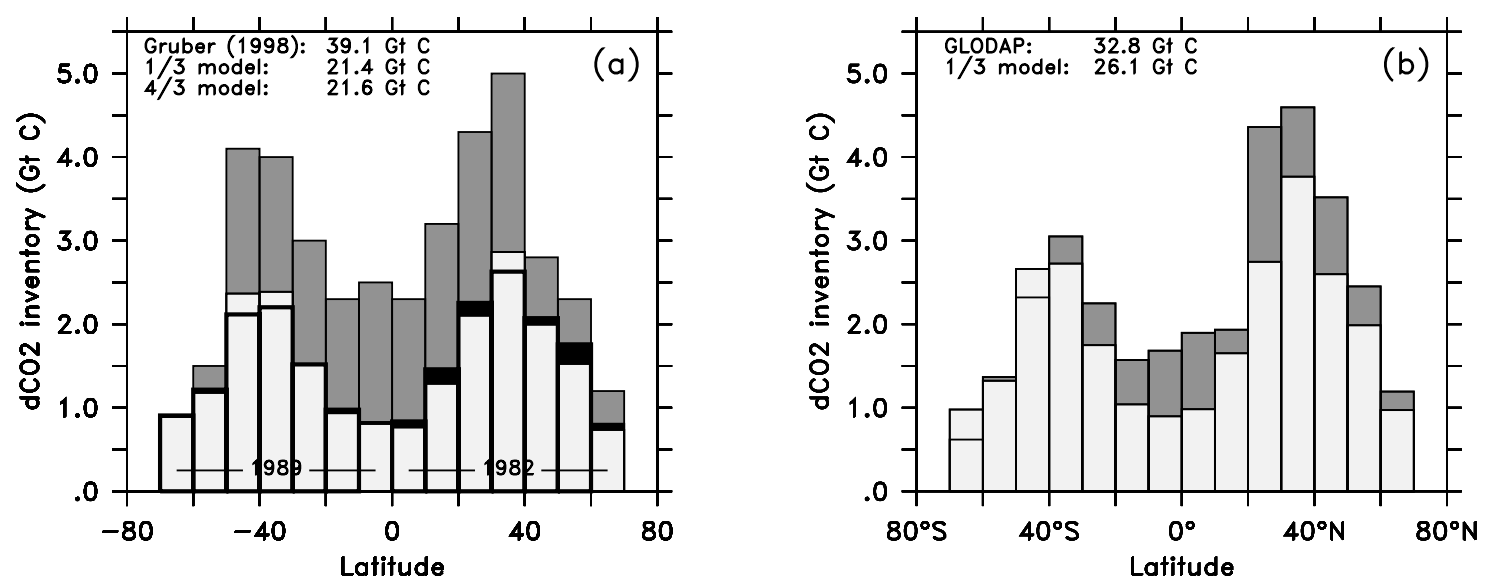

Figure 3. (a) Latitudinal dependence of vertically integrated $\mathrm{C}_{\mathrm{ant}}$ inventory of the two models $\left(4 / 3^{\circ}\right.$ : black, $1 / 3^{\circ}$ : light gray). Similar to the analysis of Gruber [1998] (dark gray) inventories for the North Atlantic were calculated from year 1982, for the South Atlantic from year 1989. (b) Similar for $1 / 3^{\circ}$ model, year 1990, and GLODAP data [Sabine et al., 2004] (dark gray).

oceanic $p \mathrm{CO}_{2}$ is an effect of the annual temperature cycle, not of biological activity, as we are assuming a steady state pre-industrial carbon cycle. For the bulk of analysis we therefore concentrate on the interannual variability. Only for a detailed comparison of differences in uptake between $\mathrm{C}_{\mathrm{ant}}$ and CFC in respect to wintertime convection we focus on the intraseasonal timescale.

\section{Basin-Scale Budget of $\mathbf{C}_{\text {ant }}$}

[17] The spatial pattern of the vertically integrated $C_{a n t}$ inventory in the $4 / 3^{\circ}$ model (Figure $2 \mathrm{a}$ ) agrees with results from other coarse-resolution models [Sarmiento et al., 1992; Caldeira and Duffy, 2000; Orr et al., 2001] and data-based estimates [Sabine et al., 2004]. It shows the major storage of $\mathrm{C}_{\mathrm{ant}}$ in the subpolar North Atlantic and a broad southward spreading west of the Mid-Atlantic Ridge. A somewhat weaker southward spreading occurs in the eastern basin.

[18] Qualitatively, the pattern in the eddy-permitting $1 / 3^{\circ}$ model (Figure 2b) is very similar. However, owing to the better resolution of the western boundary structures and the resulting Deep Western Boundary Current (DWBC), a more confined spreading along the western margin transports $C_{a n t}$ faster to the south and across the equator than in the coarse resolution model. The result of this spreading is a stronger connection of North and South Atlantic than in the $4 / 3^{\circ}$ model. In the subpolar basin the west-east gradient of $\mathrm{C}_{\mathrm{ant}}$ is increased owing to a more realistic representation of bottom topography and the resulting narrower passages, such as the Gibbs Fracture Zone, leading to less transport of Labrador Sea Water (LSW) into the eastern basin. The strong meridional gradient agrees well with the strong east-west gradient in observational $\mathrm{C}_{\mathrm{ant}}$ estimates by Körtzinger et al. [1999]. A detailed comparison of $\mathrm{CFC}$ and $\mathrm{C}_{\mathrm{ant}}$ data with recent ship measurements in the midlatitude North Atlantic shows that the $1 / 3^{\circ}$ model compares well in both structure and values [Tanhua et al., 2006]. The model showed a remarkable agreement with the increase in both $\mathrm{CFC}$ and total inorganic carbon over the last 20 years as inferred from a comparison of recent observations with TTO data.

[19] The latitudinal distribution of $\mathrm{C}_{\text {ant }}$ is confronted with data-based estimates in Figure 3, averaged over $10^{\circ}$ latitude bands and referenced to a common year. The comparison indicates qualitatively similar latitudinal dependence but shows that both model runs contain significantly less $C_{a n t}$ than the estimate by Gruber [1998] (Figure 3a), except in the most southern latitude band. In the subtropical regions of both hemispheres, the inventory in the $1 / 3^{\circ}$ model is higher, and thus closer to the estimate by Gruber [1998] than the $4 / 3^{\circ}$ model; the converse holds in the subpolar and tropical regions. The total amount of $\mathrm{C}_{\mathrm{ant}}$ in the two model resolutions is almost equal.

[20] The discrepancy between the models and the more recent compilation by GLODAP [Sabine et al., 2004] is less drastic (Figure 3b). The total model inventory is only 55\% of the estimate by Gruber [1998], but $80 \%$ of the more recent estimate by Sabine et al. [2004].

[21] What is the cause for the discrepancy between the model and data-based inventory estimates? One possible cause on the model side could be an underestimation of the air-sea flux of $\mathrm{C}_{\mathrm{ant}}$. A wide variety of conditions have been shown to influence air-sea gas exchange, among them wave breaking and bubbles, surface films, the thermal skin effect, etc. [e.g., Woolf, 1997; Zappa et al., 2001; Frew et al., 2004; McGillis and Wanninkhof, 2006]. No consensus has been reached on how best to parameterize these effects [Wanninkhof and McGillis, 1999; McGillis et al., 2000; Woolf, 2005]; when using measured distributions of $p \mathrm{CO}_{2}$, global air-sea flux of $\mathrm{CO}_{2}$ is quite sensitive to the choice of gas exchange parameterizations [Takahashi et al., 2002].

[22] To clarify this point, we performed three model experiments with the $4 / 3^{\circ}$ model, all using the same wind speed distribution obtained from 6-hourly NCEP wind fields as in the reference run: Two experiments were conducted with doubled or halved gas exchange velocity, maintaining the quadratic wind-speed dependency. A third experiment used the cubic wind-speed dependency of Wanninkhof and McGillis [1999]. The area-integrated air- 


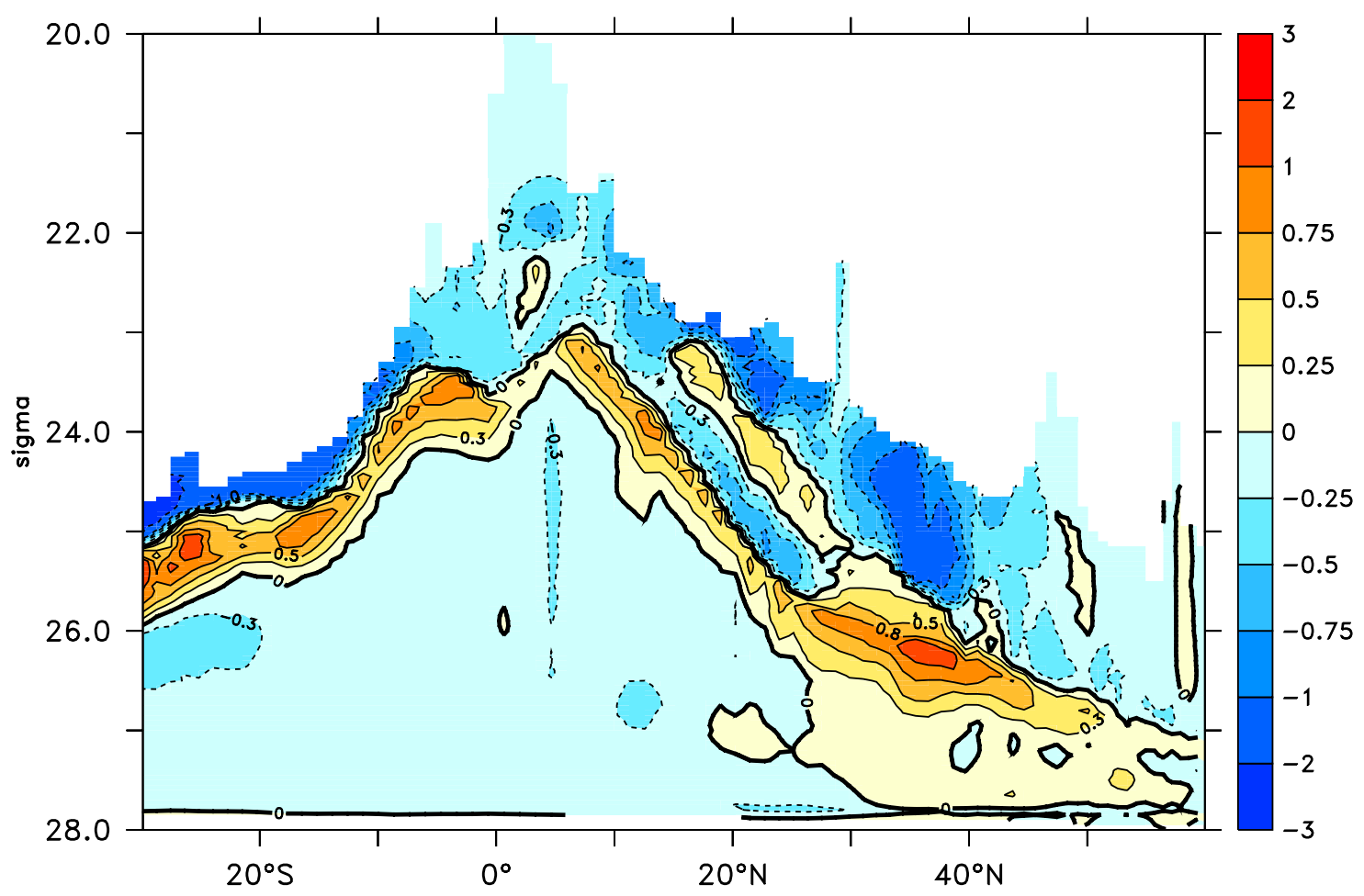

Figure 4. Difference $1 / 3^{\circ}$ minus $4 / 3^{\circ}$ model in the zonally integrated $\mathrm{C}_{\mathrm{ant}}$ inventory (in $\mathrm{Mt} \mathrm{C} / \mathrm{m}^{2}$ ) as a function of latitude and potential density $\sigma_{\theta}$.

sea-flux with halved gas exchange velocity is $18 \%$ lower compared to the reference run, $6 \%$ higher with the cubic wind speed dependency, and $13 \%$ higher for the doubled gas exchange velocity. This low sensitivity agrees with findings from earlier model studies [e.g., Sarmiento et al., 1992; England et al., 1994] and can be explained by the tendency of the air-sea disequilibrium in prognostic carbon models to become smaller for increased gas exchange velocity, partially offsetting the increased flux due to the gas exchange velocity. This cannot happen when using observed $p \mathrm{CO}_{2}$ [Takahashi et al., 2002], explaining the stronger sensitivity found in data-based flux calculations. The average gas exchange velocity in the reference run is $18 \mathrm{~cm} \mathrm{hr}^{-1}$, only slightly lower than the global average estimated by Broecker et al. [1986] of $22 \mathrm{~cm} \mathrm{hr}^{-1}$. We therefore conclude that uncertainties in the gas-exchange have only a minor effect on our modeled $\mathrm{C}_{\text {ant }}$ inventory.

[23] Another possible reason could be a too low formation rate of North Atlantic Deep Water (NADW) or of Subtropical Mode Water (STMW). The LSW inventory of CFCs in this model has, however been shown to be in close agreement with observations [Böning et al., 2003], so that we can probably exclude a too weak NADW formation rate as the main cause. Also, both meridional overturning and heat transport are close to data-based estimates [Talley, 2003; MacDonald and Wunsch, 1996].

[24] Concerning the role of STMW in the carbon uptake, it is instructive to compare the formation rates and $\mathrm{C}_{\mathrm{ant}}$ inventories in the $1 / 3^{\circ}$ and $4 / 3^{\circ}$ models. The volume of STMW (density range $\sigma=26-26.7$ ) is with $3.6 \times 10^{6} \mathrm{~km}^{3}$ (total amount in the subtropical North Atlantic) correctly simulated in the $1 / 3^{\circ}$ model compared to Levitus observations $\left(3.7 \times 10^{6} \mathrm{~km}^{3}\right)$, whereas the $4 / 3^{\circ}$ model under- estimates this volume by $25 \%\left(3.7 \times 10^{6} \mathrm{~km}^{3}\right)$. Although STMW only represents $5 \%$ of the total water mass it contains with $20 \%$ a significant amount of $\mathrm{C}_{\text {ant }}$. Therefore increasing STMW by only small amounts would result in an disproportionally large gain of $\mathrm{C}_{\mathrm{ant}}$. Comparing the inventories between $20^{\circ} \mathrm{N}$ and $40^{\circ} \mathrm{N}$ in both models (Figure 3a) one notes an increased uptake the subtropics. However, comparing the density ranges of $\mathrm{C}_{\text {ant }}$ (Figure 4) reveals that this increase does only has little effect on the total uptake. At the same latitude there is also a partial decrease of the inventory in lighter water masses, so that the total inventory does not change significantly.

[25] The limited model domain could also influence inventories through the prescribed $\mathrm{C}_{\text {ant }}$ values at the lateral boundaries in the Southern Ocean. The values were obtained by using a relation between $\mathrm{CFCs}$ and $\mathrm{C}_{\mathrm{ant}}$ estimated from present-day data. Because $\mathrm{C}_{\text {ant }}$ has a longer atmospheric history than CFCs it is possible that older water masses contain $\mathrm{C}_{\mathrm{ant}}$ but no CFCs; however, our estimate at $30^{\circ} \mathrm{E}$ agrees well with the more recent estimate of $\mathrm{C}_{\mathrm{ant}}$ along that latitude by Lo Monaco et al. [2005b, 2005a]. If anything, we expect the boundary condition to lead to a slight overestimation of $\mathrm{C}_{\mathrm{ant}}$ in earlier periods of the model integration, when our estimate overestimates the penetration depth of the signal. Moreover, most of the signal entering in Drake Passage leaves the model domain again over the boundary to the Indian Ocean.

[26] The initialization of the model in 1900 with no $C_{\text {ant }}$ present clearly is an underestimate; however, most of the initial deficit is compensated by a rapid initial equilibration in the first few years of the model run (Figure 1). For the $4 / 3^{\circ}$ model we estimate the remaining deficit in the year 1900 to be less than $1 \mathrm{Pg} \mathrm{C}$ or $4 \%$, using a fit to the Green function 

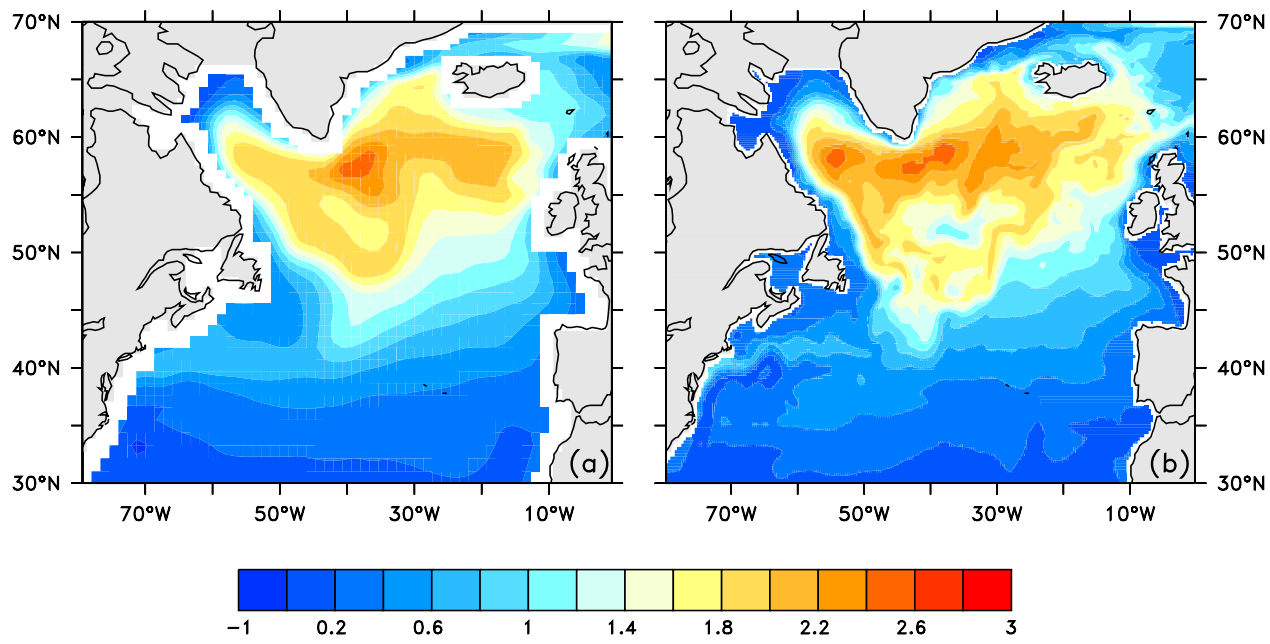

Figure 5. Average 1989 atmosphere-ocean flux of $\mathrm{C}_{\text {ant }}$ (in mol m${ }^{-2}$ year $^{-1}$ ) in the (a) $4 / 3^{\circ}$ and in the (b) $1 / 3^{\circ}$ model.

for the model inventory by two exponentials. The assumption of an unchanged strength of the biological pump might be wrong. However, the predicted feedbacks of climate change on the biological pump in the ocean at least for the present are much to weak to account for the inventory difference here, and also generally in the opposite direction [Friedlingstein et al., 2003].

[27] The assumptions of (1) a preindustrial equilibrium between ocean and atmosphere $p \mathrm{CO}_{2}$ at (2) constant alkalinity in the perturbation approach are both wrong. However, the effects of these two errors on equilibrium $\mathrm{C}_{\text {ant }}$ are small and have opposing signs for the North Atlantic.

[28] In summary, we cannot identify one dominating cause that can explain the lower $\mathrm{C}_{\mathrm{ant}}$ inventory in our model compared to the data-based inventories of Gruber [1998] and Sabine et al. [2004]. Instead there are a number of uncertainties that possibly each contribute an uncertainty of a few percent. We would argue therefore that our model estimate, while clearly low, is not completely unreasonable and probably has an uncertainty of about the same magnitude as the data-based inventories. It is within the quoted $20 \%$ error limit [Gruber et al., 1996] of the data-based inventory by Sabine et al. [2004], but clearly outside the error limits of the Gruber [1998] inventory. The accuracy of the data-based estimates is still a matter of much debate [Hall et al., 2004; Waugh et al., 2004; Matsumoto and Gruber, 2005; Lo Monaco et al., 2005b]. Quite recently there are other studies calculating the amount of $\mathrm{C}_{\text {ant }}$ by
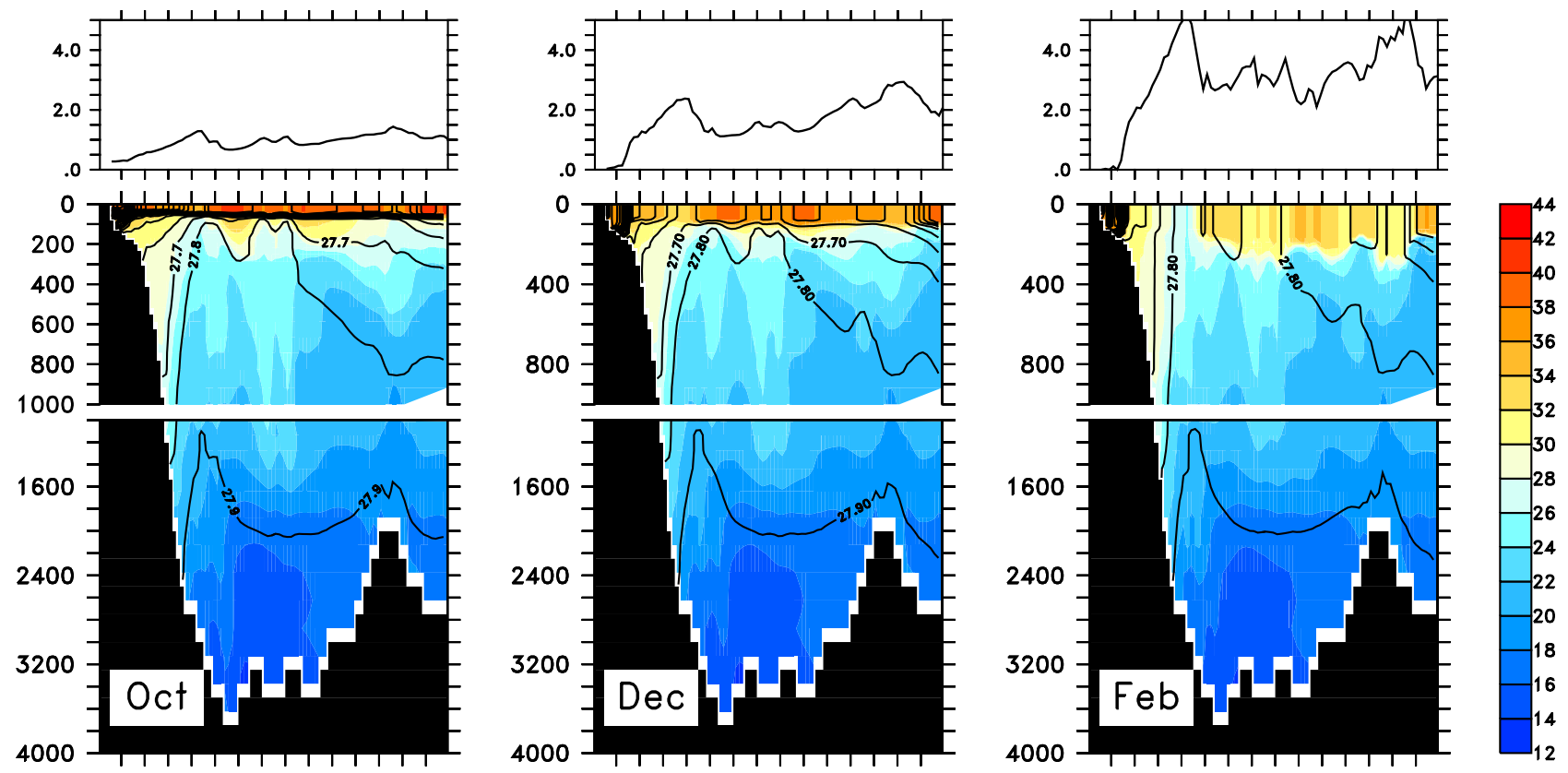

Figure 6. Zonal section at $55^{\circ} \mathrm{N}$ of $\mathrm{C}_{\text {ant }}$ in $\mu \mathrm{mol}^{-1}$ for different months during winter 1994/1995. The isolines show the density structure in sigma units, the atmosphere-ocean flux of $\mathrm{C}_{\mathrm{ant}}\left(\right.$ in $\mathrm{mol} \mathrm{m}^{-2} \mathrm{yr}^{-1}$ ) is shown on top. 

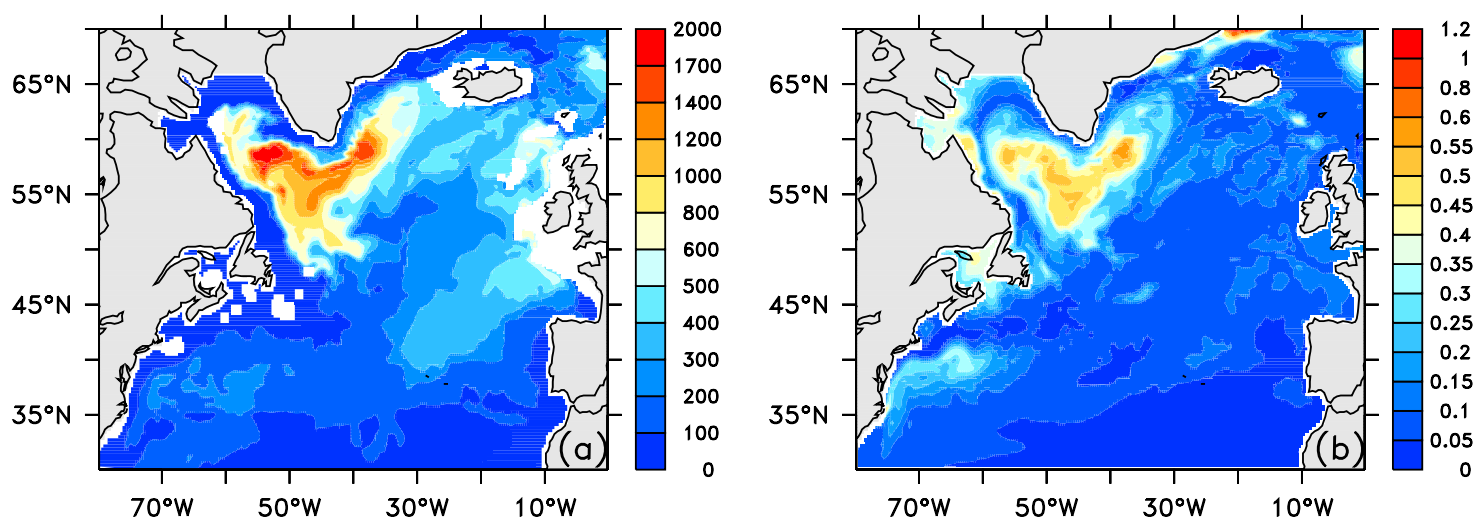

Figure 7. (a) Mixed layer depth (in meters) in the $1 / 3^{\circ}$ model (REF), March 1989. (b) Annual average as Figure $5 \mathrm{~b}$ but CFC-11 flux in $\mathrm{mmol} \mathrm{m} \mathrm{m}^{-2} \mathrm{yr}^{-1}$.

using transit time distributions constrained by other data (usually CFC). By allowing mixing, Hall et al. [2004] and Waugh et al. [2004] calculated 20-30\% lower values compared to the Gruber method. An additional air-sea disequilibrium would account for another $6 \%$.

[29] Despite the as yet unexplained difference in total inventory we argue that the increased physical resolution of the model allows a better understanding of processes involved in the physical transport of $\mathrm{C}_{\text {ant }}$. The horizontal distribution of $\mathrm{C}_{\mathrm{ant}}$ (Figure 2) and of $\mathrm{C}_{\mathrm{ant}}$ air-sea flux (Figure 5) both show much more detailed structures under the effect of mesoscale eddies and frontal structures than in the coarse resolution simulation. The remainder of the paper concentrates on the physical effects that cause the horizontal structure and the temporal variability. The focus is on the subpolar North Atlantic because this is a key region in terms of deep water formation.

\section{Spatial Structure of the North Atlantic Air-Sea Flux of $\mathrm{C}_{\text {ant }}$}

\subsection{Role of Wintertime on the Anthropogenic Gas Uptake}

[30] The air-sea flux of $\mathrm{C}_{\text {ant }}$ in our model shows maximum rates over large parts of the subpolar gyre in the North Atlantic (Figure 5), consistent both in strength and pattern with the coarser-resolution global models of $\mathrm{Orr}$ et al. [2001]. While the $4 / 3^{\circ}$ model has a broad, uniform uptake over large areas, the uptake flux in the $1 / 3^{\circ}$ model shows a more complex pattern, suggestive of a relation to the circulation structure in the subpolar gyre, which is substantially refined in the higher-resolution model.

[31] What are the main processes controlling this pattern? A first assumption would be that $C_{\text {ant }}$ fluxes should be affected the formation of deep water masses through wintertime convection. Cooling through strong winds at the end of winter leads to an unstable water column, causing denser surface water to mix down to a depth where it is neutrally stable with respect to the surrounding water masses. Figure 6 demonstrates how this process affects $\mathrm{C}_{\mathrm{ant}}$ uptake along a section at $55^{\circ} \mathrm{N}$ : In fall (Oct) the water column is stable with a shallow mixed layer. The surface waters are highly saturated with $\mathrm{C}_{\mathrm{ant}}$, and the flux from the atmosphere into the ocean is low. Later in fall (Dec) the mixed layer deepens, $\mathrm{C}_{\mathrm{ant}}$ is mixed down, and the surface mixed layer is able to take up additional $\mathrm{C}_{\text {ant }}$ which causes the atmosphereocean flux to increase more or less uniformly. In late winter (Feb) local deep-reaching convection occurs, and $\mathrm{C}_{\mathrm{ant}}$ enriched surface water mixes with deep water with a very low $\mathrm{C}_{\text {ant }}$ content, causing high $\mathrm{C}_{\text {ant }}$ fluxes over small scales. An imprint of small-scale wintertime process remains visible in the annual average (Figure 5b).

[32] However, the process of deep water formation is restricted to the Labrador and Irminger Seas (as evidenced by the late winter mixed layer depth, Figure 7a), and some other process must be invoked to explain the extended flux pattern across the subpolar gyre: a conspicuous feature to be noted here is the apparent correspondence of the $\mathrm{C}_{\mathrm{ant}}$ flux with the upper ocean current system, particularly along the path of the North Atlantic Current and the recirculation within the Irminger Basin (Figure 5b).

[33] Since CFC-11 has a much shorter equilibration time with the atmosphere compared to $\mathrm{C}_{\mathrm{ant}}$ we might expect a different role of the short-term, deep-winter convection processes on its uptake. The annual averaged flux pattern (Figure 5b) is indeed much more concentrated than the $\mathrm{C}_{\text {ant }}$ flux. Comparing Figure $5 \mathrm{~b}$ with the annual mean air-sea flux of CFC-11 from the model (Figure 7b), we clearly see a good match with the spots of wintertime deep convection (Figure 7a) in the Irminger and Labrador Seas in Figure 7a.

[34] Although the atmospheric input for both tracers does not feature a seasonal cycle, Figure 6 already indicated that the oceanic response has a clear variation within one year. Figure 8 shows the variations of $\mathrm{C}_{\mathrm{ant}}$ and $\mathrm{CFC}-11$ atmosphere-ocean fluxes in the subpolar North Atlantic where one clearly identifies an increased uptake in winter. In summer the uptake for both tracers shows a minimum; but while the CFC uptake decreases down to zero, $\mathrm{C}_{\text {ant }}$ flux is still present throughout the whole year. A direct comparison of normalized fluxes (Figure 8, bottom) illustrates the difference between the equilibration timescales of $\mathrm{C}_{\text {ant }}$ and CFC-11: For CFC-11, the uptake is mainly restricted to the winter season. In summer the surface mixed layer becomes almost completely saturated and the flux is basically zero. $\mathrm{C}_{\mathrm{ant}}$, in contrast, has a 10 times longer equilibration time than CFCs, and in addition the atmospheric $p \mathrm{CO}_{2}$ continues 


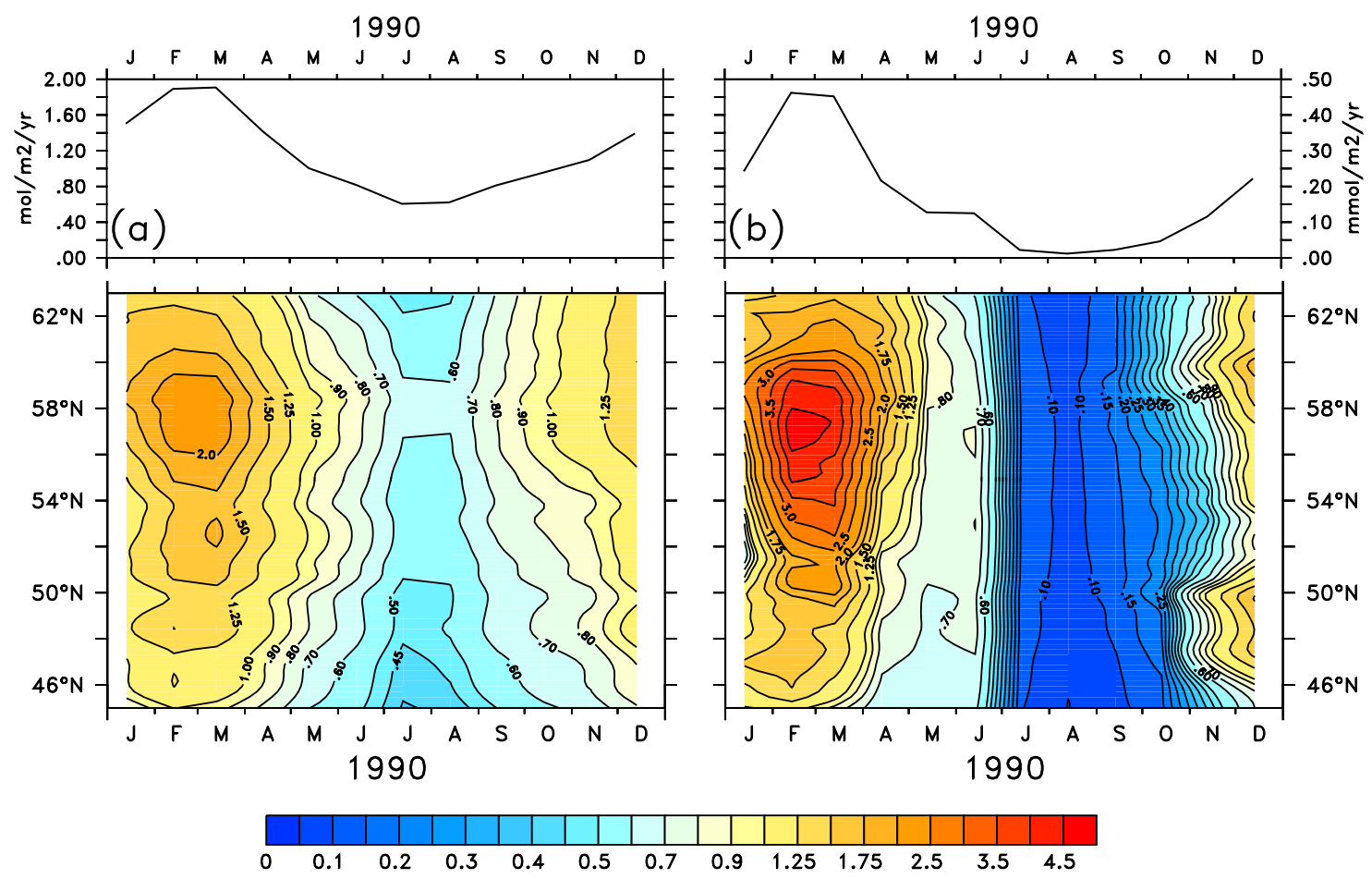

Figure 8. Atmosphere-ocean fluxes of (a) $\mathrm{C}_{\text {ant }}$ (in $\mathrm{mol} \mathrm{m}^{-2} \mathrm{yr}^{-2}$ ) and (b) CFC-11 (top) in 1990 (in $\mathrm{mmol} \mathrm{m} \mathrm{yr}^{-2}$ ), averaged over the latitudinal band $45-53^{\circ} \mathrm{N}$. (bottom) The relative (i.e., normalized by a spatial and time mean of the individual fields) fluxes of $\mathrm{C}_{\text {ant }}$ and CFC-11.

to increase, while $p$ CFC-11 already has stopped increasing in the 1990s. Therefore the upper ocean is basically never in equilibrium with the atmosphere for $\mathrm{C}_{\text {ant }}$, and atmosphereocean flux pertains over the whole year. This also implies that $\mathrm{C}_{\mathrm{ant}}$ flux is not as limited to regions of wintertime deep convection as that of CFC-11 (or any other trace gas that also has a fast equilibration time).

\subsection{Quantitative Assessment of the $\mathbf{C}_{\text {ant }}$ Air-Sea Flux}

[35] Direct validation of the modeled $\mathrm{C}_{\text {ant }}$ fluxes using inverse estimates of $\mathrm{C}_{\mathrm{ant}}$ uptake [Gloor et al., 2003; Mikaloff Fletcher et al., 2006] is difficult, as these contain a number of assumptions, and resolve only patterns on scale of whole ocean gyres. In models, however, we can gain a better mechanistic understanding how the uptake of $\mathrm{C}_{\mathrm{ant}}$ is driven, and validate whether these mechanisms are represented correctly in the model.

[36] The spatial and temporal distribution of the air-sea flux of $\mathrm{C}_{\mathrm{ant}}$ can be understood as the result of the interplay between three driving processes:

[37] 1. First, there is a continuing increase of anthropogenic carbon in the atmosphere. In equilibrium, this increase would be accompanied by a corresponding increase of $\mathrm{C}_{\mathrm{ant}}$ in the surface mixed layer of the ocean. The discrepancy between the 'new' equilibrium and the actual $\mathrm{C}_{\mathrm{ant}}$ concentration drives air-sea flux.

[38] 2. Second, water within the mixed layer experiences temperature changes while being moved about. Owing to the temperature dependency of the carbonate chemistry in seawater, the equilibrium concentration of $\mathrm{C}_{\mathrm{ant}}$ is positively correlated with temperature; that is, an increase in temperature leads to an increase in $\mathrm{C}_{\mathrm{ant}}$ content in equilibrium for a given $p \mathrm{CO}_{2}$ [Wallace, 2001; Völker et al., 2002]. This is in contrast to the behavior of total $\mathrm{CO}_{2}$ which, for a given $p \mathrm{CO}_{2}$, increases with decreasing temperature. As before, the difference between equilibrium and the actual $\mathrm{C}_{\mathrm{ant}}$ concentration drives air-sea flux.

[39] 3. Third is the entrainment into the mixed layer of older water from below containing different, usually less or no $\mathrm{C}_{\mathrm{ant}}$. This entrainment can be caused by the annual cycle of mixed-layer depth or by lateral or vertical advection into the mixed layer.

[40] To investigate more quantitatively the role of the three driving processes of $\mathrm{C}_{\text {ant }}$ uptake enumerated in the beginning of this section, we analyze the Lagrangian rate of change of $\mathrm{C}_{\mathrm{ant}}$ of a water column that moves horizontally in the mixed layer of the ocean.

[41] Following Follows and Williams [2004], we define $C^{\prime}$ as the mixed-layer disequilibrium in $\mathrm{C}_{\mathrm{ant}}$; that is, the difference between the value that would be in equilibrium for a given $p \mathrm{CO}_{2}$ and the actual $\mathrm{C}_{\mathrm{ant}}, \mathrm{C}^{\prime}=\mathrm{C}_{\mathrm{ant}}^{\mathrm{eq}}-\mathrm{C}_{\mathrm{ant}}$. From the mass balance for $\mathrm{C}_{\mathrm{ant}}$ averaged over the mixed layer depth $h$ one obtains

$$
\frac{D C^{\prime}}{D t}+\frac{F}{h}=E_{1}+E_{2}+E_{3}
$$

where $F$ is the air-sea flux of $\mathrm{C}_{\text {ant }}$ and the three terms on the right hand side stem isolate the forcing by the three processes mentioned in the begin of the section in the order that they appear there. They can be analyzed using an annual cycle of monthly average velocity and tracer fields from the model run and then forming an annual average. 

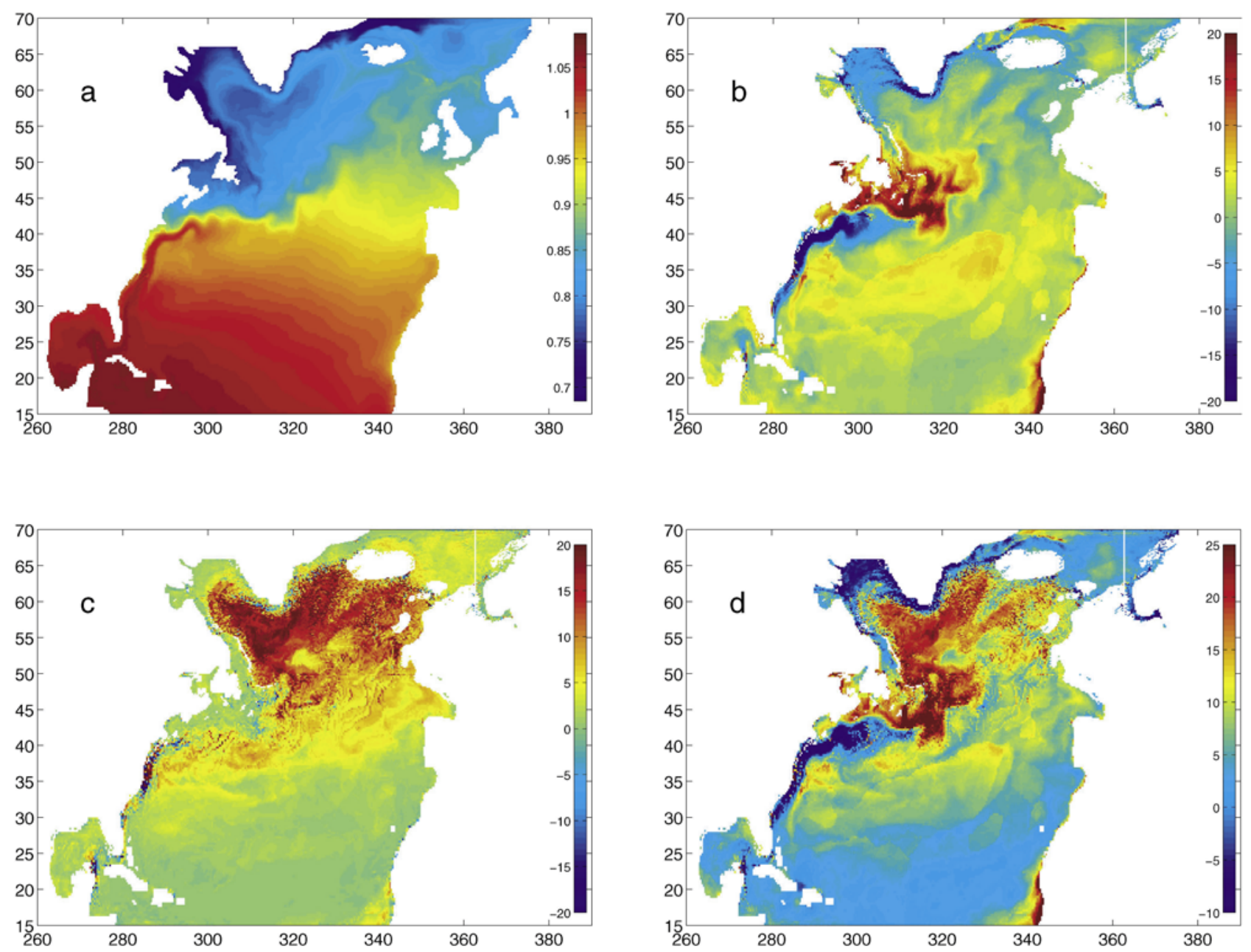

Figure 9. Terms appearing on the right-hand side of equation (1) (in mmol $\mathrm{C}_{\mathrm{ant}} \mathrm{m}^{-3} \mathrm{a}^{-1}$ ) calculated using an annual cycle of monthly average fields from the model run. Note the different color scale used in the plots. (a) Term corresponding to the increase in $p \mathrm{CO}_{2}, E_{1}$, equation (2). (b) Term caused by temperature changes $E_{2}$, equation (3). (c) Term due to exchange with water from below $E_{3}$, equation (5).

(d) Sum of all three terms $E_{1}+E_{2}+E_{3}$.

[42] $E_{1}$ corresponds to increasing $p \mathrm{CO}_{2}$ and is defined by:

$$
E_{1}=\frac{\partial \mathrm{C}_{\mathrm{ant}}^{\mathrm{eq}}}{\partial p \mathrm{CO}_{2}} \frac{\partial p \mathrm{CO}_{2}}{\partial t}
$$

where $\mathrm{C}_{\mathrm{ant}}^{\mathrm{eq}}$ is the concentration of $\mathrm{C}_{\mathrm{ant}}$ in equilibrium with the instantaneous $p \mathrm{CO}_{2}$. As we are using the SiegenthalerSarmiento approximation for anthropogenic carbon, the first term on the right hand side can be calculated from mixedlayer temperature and atmospheric $p \mathrm{CO}_{2}$. The result is shown in Figure 9a. The spatial structure of that term mainly reflects that of the sea-surface temperature. Highest values are found where temperature is high, reflecting the temperature dependency of the Revelle or buffer factor.

[43] The term $E_{2}$ corresponds to heat flux forcing and is:

$$
E_{2}=\frac{\partial \mathrm{C}_{\mathrm{ant}}^{\mathrm{eq}}}{\partial T} \frac{D T}{D t}
$$

where $D T / d t$ is the Lagrangian derivative of the mixed-layer temperature. Again, the first term on the rhs. can be evaluated from mixed-layer temperature and atmospheric $p \mathrm{CO}_{2}$, using the Siegenthaler-Sarmiento approach. The second term can be evaluated from the Lagrangian form of the internal energy balance for the mixed layer:

$$
\frac{D T}{D t}=\frac{Q}{\rho c_{p} h}+E_{T}
$$

where $Q$ is the surface heat flux, and $E_{T}$ is the rate of change of temperature due to the entrainment of water of different temperature from below. The result of the calculation using model fields is shown in Figure 9b. Note that the range of values is much larger than in Figure 9a. The largest values are reached around the equator and in the southern end of the subpolar gyre where heat fluxes are strongly positive. The pattern differs quite strongly from the pattern of annually averaged heat-flux alone: over the large areas of the subtropical and subpolar North Atlantic the values of $E_{2}$ are positive although heat fluxes are negative. This is explained by the rectifying effect of the temporal covariance between heat flux and mixed layer depth, as shown in 


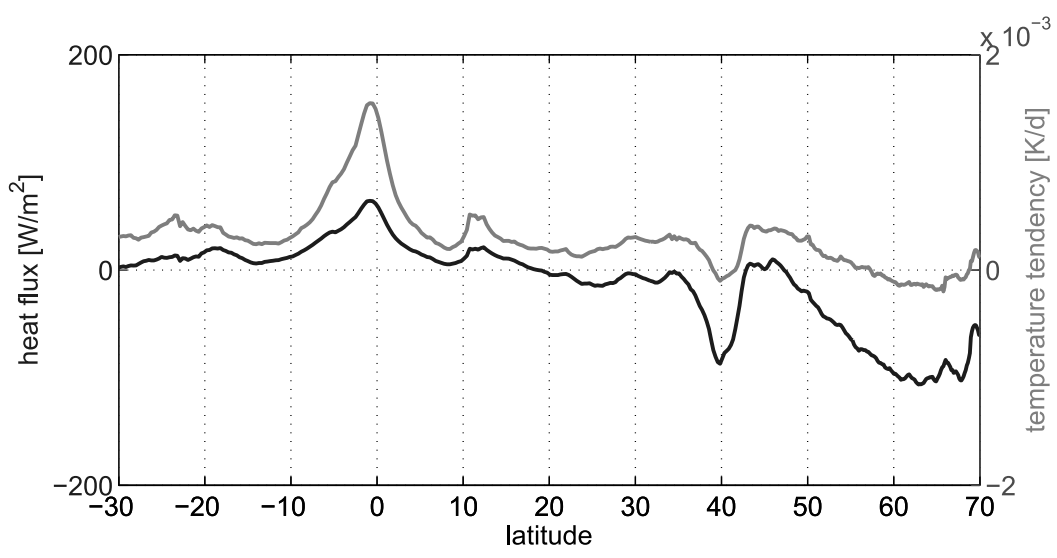

Figure 10. Comparison of the temporal and zonal average of the heat flux $Q$ (black, left axis) and of the resulting rate of change of temperature in the mixed layer $Q /\left(\rho c_{p} h\right)$ (gray, right axis).

Figure 10: the annual average of $Q /\left(\rho c_{p} h\right)$ can be positive even when the average heat flux $Q$ is strongly negative if, over the annual cycle, positive values of $Q$ are more likely to occur during times of shallow mixed layer than negative values. Advective contributions to $E_{2}$ are generally small.

[44] The term $E_{3}$ finally describes the change of $\mathrm{C}_{\text {ant }}$ by vertical entrainment. Concentrations within the mixed layer change only when the mixed layer is deepening, entraining water from below with a different $C_{a n t}$, not when it is shallowing. This leads to:

$$
E_{3}=\left\{\begin{array}{lll}
0 & \text { if } & \frac{D h}{D t}<=0 \\
\frac{1}{h} \frac{D h}{D t}\left(\mathrm{C}_{\mathrm{ant}}^{b}-\mathrm{C}_{\mathrm{ant}}\right) & \text { if } & \frac{D h}{D t}>0 .
\end{array}\right.
$$

where $D h / D t$ is the Lagrangian time derivative of mixed layer depth, and $\mathrm{C}_{\mathrm{ant}}^{\mathrm{b}}$ is the anthropogenic carbon concentration in the entrained water below the mixed layer. Note that this definition of entrainment corresponds to the definition of 'detrainment' as used in studies of mode water ventilation [e.g., Marshall et al., 1993]. The distribution of $E_{3}$ (Figure 9c) is dominated by the influence of the annual mixed layer cycle over most of the subpolar domain and by lateral entrainment over large parts of the
Gulf stream region. The values of $E_{3}$ are high throughout the entire subpolar North Atlantic, not only over the main convection regions in the Labrador and Irminger seas.

[45] The sum of all three forcing terms $E_{1}+E_{3}+E_{3}$ is shown in Figure 9d. It exhibits maximum values over the Labrador and Irminger seas related to vertical exchange, but another, very pronounced maximum at the southern end of the subpolar gyre, off Newfoundland, that is caused by the ocean heat gain. For an infinitely fast gas exchange, $E_{1}+E_{3}+E_{3}$ should be equal to the annual mean of $F / h$, the $\mathrm{C}_{\text {ant }}$ air-sea flux divided by the mixed layer depth (equation (1)). Owing to the long equilibration time of $\mathrm{C}_{\mathrm{ant}}$, however, the maximum values of $F / h$ are shifted downstream relative to those of $E_{1}+E_{3}+E_{3}$. We can therefore attribute the increased $\mathrm{C}_{\text {ant }}$ flux rates along the path of the North Atlantic Current and its recirculation in the Irminger Basin, shown in Figure 5b, primarily to the heat-flux forcing off Newfoundland.

[46] Over most of the subpolar gyre, the entrainment terms dominates the forcing of air-sea flux, while the temperature-related forcing dominates over the subtropics (Figure 11). The term caused by the temporal increase in $p \mathrm{CO}_{2}$ is only a minor Contribution; that is, even if the increase of anthropogenic carbon in the atmosphere was

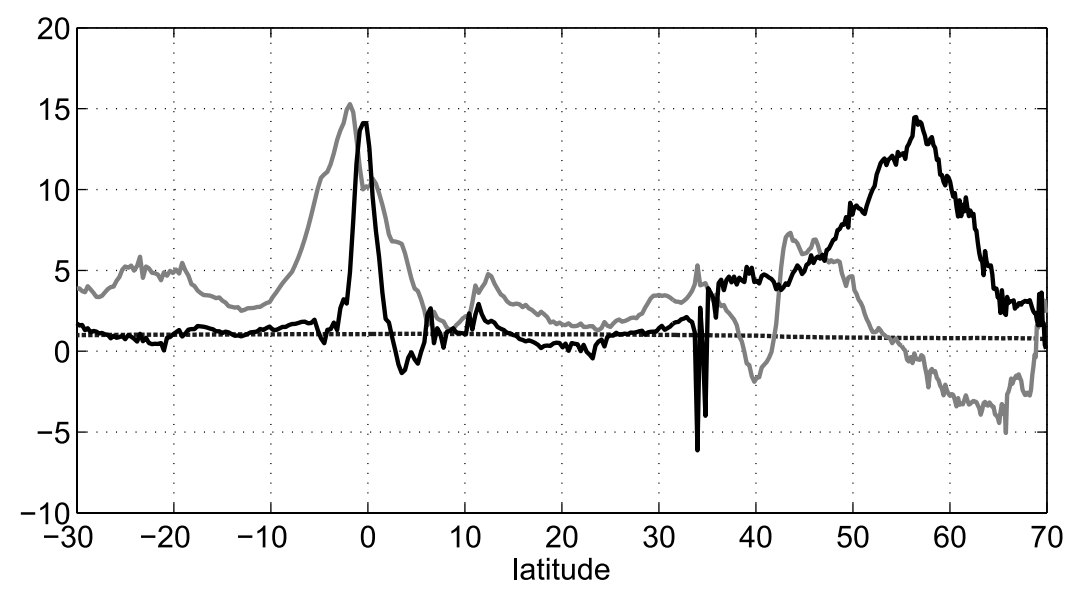

Figure 11. Zonal average of the three terms $E 1$ (dotted line), $E_{2}$ (gray solid line), and $E_{3}$ (black solid line) shown in Figures $9 \mathrm{a}-9 \mathrm{c}$ for the tropical and North Atlantic. 

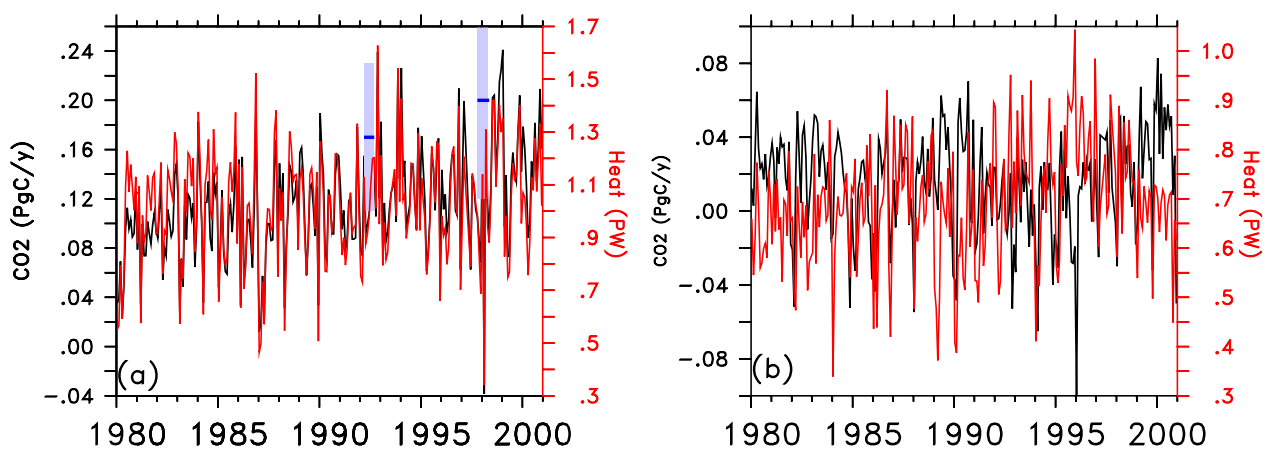

Figure 12. Meridional $\mathrm{C}_{\text {ant }}$ (black, in $\mathrm{Pg} \mathrm{C} / \mathrm{yr}$ ) and heat (red, in $\mathrm{PW}$ ) transport across (a) $25^{\circ} \mathrm{N}$ and (b) $45^{\circ} \mathrm{N}$. Also shown in blue are the estimates of anthropogenic carbon transport at $20^{\circ} \mathrm{N}$ by [MacDonald et al., 2003].

stopped, the ocean would continue taking up $\mathrm{C}_{\mathrm{ant}}$ at a similar rate for some time.

[47] One could make a similar calculation also with respect to CFC flux. However, because the equilibrium concentration of CFC decreases with increasing temperature while the converse hold for $\mathrm{C}_{\mathrm{ant}}$, one can immediately infer, that the forcing term corresponding to $E_{2}$ (i.e., the heat-flux related forcing) must have the opposite sign from that of $\mathrm{C}_{\text {ant }}$. We therefore do not expect a similar forcing of uptake off Newfoundland, and thus no enhanced uptake along the path of the North Atlantic current downstream.

\section{Temporal Variability of the $\mathbf{C}_{\mathrm{ant}}$ Transport}

[48] Observational studies agree that the transport of $\mathrm{C}_{\mathrm{ant}}$ is directed northward, opposite to the transport of total dissolved inorganic carbon, throughout the tropical and subtropical Atlantic [Holfort et al., 1998; MacDonald et al., 2003; Roson et al., 2003]. Nevertheless, some controversy still exists on the size of that transport. This has led to contradicting inferences about the magnitude and even the sign of the air-sea flux of $\mathrm{C}_{\text {ant }}$ within the North Atlantic basin [Wallace, 2001; Völker et al., 2002; MacDonald et al., 2003; Roson et al., 2003; Gloor et al., 2003].

[49] In agreement with these estimates, the transport of anthropogenic $\mathrm{C}_{\mathrm{ant}}$ in this model is directed northward (Figure 12) over the tropical and subtropical Atlantic. While increasing in time, the transport is subject to substantial variations on a monthly timescale that can be in the same order of magnitude as the annual mean transport. The annual mean transport at $25^{\circ} \mathrm{N}$ is $10-20 \%$ lower than the estimate of MacDonald et al. [2003], albeit still within their error estimate (see mean and error bars in Figure 12). This corresponds well to the fact that the maximum northward heat transport in the model is also lower than data-based estimates by about the same factor ( $1 \mathrm{PW}$, compared to $1.2 \pm$ 0.3 PW given by Ganachaud and Wunsch [2000]).

[50] Why does the meridional transport of $\mathrm{C}_{\mathrm{ant}}$ agree so well with the data-based estimates in contrast to the total inventory? The total inventory depends strongly on small concentrations of $\mathrm{C}_{\mathrm{ant}}$ over the intermediate and deep waters that depend on the formation, spreading, and mixing rates of the source water masses. These dependencies affect both the data-based estimates and our model results. The transport of
$\mathrm{C}_{\mathrm{ant}}$, on the other hand, is dominated by large surface values of $\mathrm{C}_{\mathrm{ant}}$ that coincide with the strongest meridional velocities. Surface concentrations of $\mathrm{C}_{\text {ant }}$ are almost in equilibrium with the atmosphere and thus not very dependent on possible model errors. Since the upper branch of the thermohaline circulation, the Florida and the Antilles Currents, are also within the range of observations, the $\mathrm{C}_{\mathrm{ant}}$ transport is well constrained.

[51] There is a good temporal correlation between the transports of $\mathrm{C}_{\text {ant }}$ and heat at $25^{\circ} \mathrm{N}$ (Figure 12a), in contrast to the situation at $45^{\circ} \mathrm{N}$ (Figure 12b). The correlation coefficient between the two transports is shown in Figure 13 as a function of latitude. Whereas monthly $\mathrm{C}_{\mathrm{ant}}$ and heat transport are highly correlated with values around 0.9 over the whole tropical and subtropical gyres the correlation breaks down sharply near $40^{\circ} \mathrm{N}$, and is almost zero in the subpolar gyre. This is explained by analyzing the correlations of the two individual transports with the maximum of the meridional overturning cell (MOC, in Sv, at the given latitude). In the subtropical North Atlantic the meridional overturning determines both transports: the differences in temperature and $\mathrm{C}_{\mathrm{ant}}$ between the upper and lower branches of the MOC are much larger than their zonal gradients,

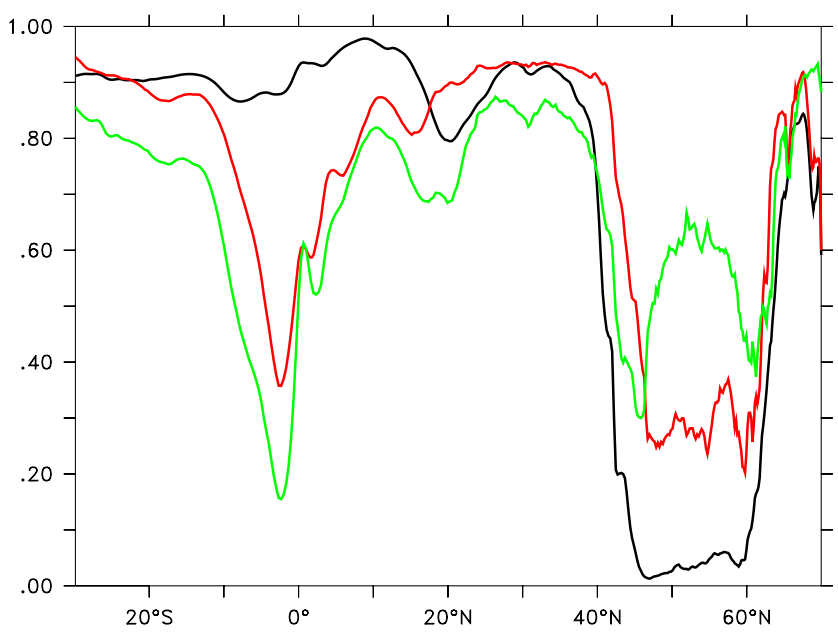

Figure 13. Correlations of meridional $\mathrm{C}_{\mathrm{ant}}$ and heat transports (black curve), of $\mathrm{C}_{\mathrm{ant}}$ transport and maximum of meridional overturning (green curve), and of heat transport and overturning (red curve). 

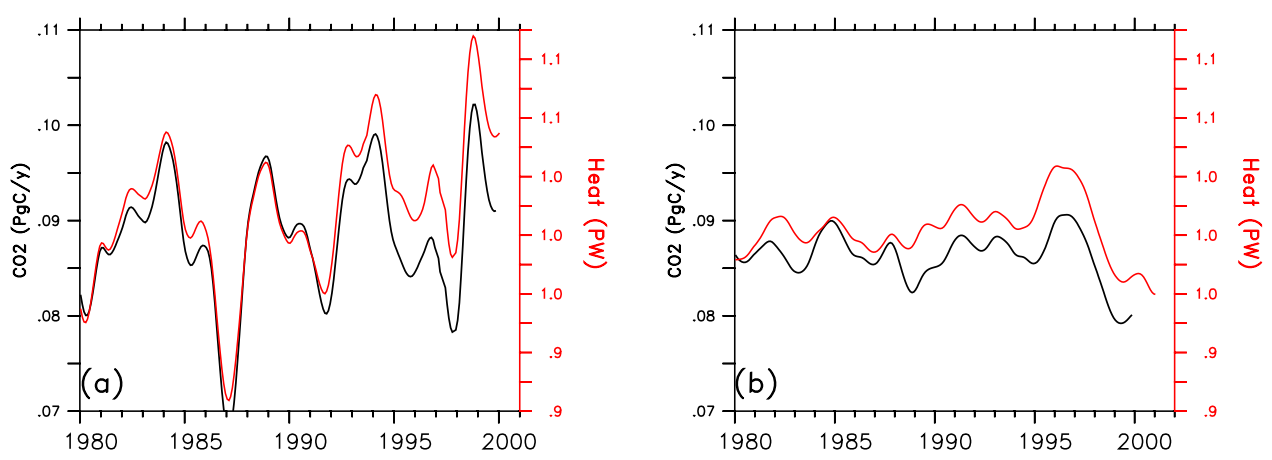

Figure 14. As in Figure 12a but for interannual transports for (a) Experiment REF and (b) Experiment HEAT. Note that $C_{\text {ant }}$ transports are detrended to remove the atmospheric increase.

leading to an only small contribution to the net northward transport by the horizontal gyre circulation. This MOC dominance does not hold in the subpolar gyre, where eastwest property gradients become much more important. However, while the heat transport-overturning correlation totally breaks down owing to the zonal contrast of warm water flowing on the eastern side (the North Atlantic Current) and cold water flowing southward on the western side (the Labrador Current), the $\mathrm{C}_{\text {ant }}$ contrast of both current regimes is much smaller than for temperature, still leaving room for a strong northward transport of $\mathrm{C}_{\mathrm{ant}}$ at the surface that is correlated to the upper branch of the meridional overturning.

[52] The almost perfect correlation at midlatitudes between the $\mathrm{C}_{\mathrm{ant}}$ and heat transports also holds on interannual-decadal timescales. Figure 14a shows both transports smoothed by a 2 -year filter removing the (intra-)seasonal variability in both time series. Although variations are now on a smaller scale $( \pm 0.1 \mathrm{PgC} /$ year $)$, the heat and $\mathrm{C}_{\text {ant }}$ transports are still are still corresponding to each other. This implies that the ongoing efforts in establishing a monitoring system for the heat transport in the North Atlantic [Hirschi et al., 2003] will also be useful for estimating the variability of $\mathrm{C}_{\mathrm{ant}}$ transports.

[53] It has already been shown that the seasonal to interannual heat transport variability at $25^{\circ} \mathrm{N}$ is primarily governed by the wind-driven (Ekman) transports and their compensation by deep return flows [Jayne and Marotzke, 2001]. Figure 14b shows that this is similar for the transport of anthropogenic carbon. In the experiment HEAT, forced by interannual heat fluxes but climatological wind stress, the year-to-year variability of $\mathrm{C}_{\mathrm{ant}}$ transport is lowered by the same amount as the heat transport. A comparison of the heat transport in this experiment with the pure climatologically forced first half of the reference experiment (not shown) indicates that interannual fluctuations are associated with the heat forcing, and not with an internally generated variability. It can be concluded that the effect of wind variability is the overall dominating mechanism causing the interannual transport fluctuations of heat and anthropogenic carbon.

\section{Summary and Discussion}

[54] The aim of this study was to explore the role of ocean physics for the uptake, transport and distribution of anthropogenic carbon in the North Atlantic with the aid of an eddy-permitting general circulation model. The model outcomes show patterns of $\mathrm{C}_{\text {ant }}$ distribution, uptake and transport that are broadly in agreement with earlier studies using less highly resolved physics. However, they also show much more spatial structure, which results, for example, in a better representation on the observed zonal gradients of $\mathrm{C}_{\mathrm{ant}}$ in the deep North Atlantic. The total inventory appears low compared to estimations by Gruber [1998] and Lee et al. [2003]. It has, however, been argued that, especially in deep waters, the back-calculation techniques for estimating $\mathrm{C}_{\mathrm{ant}}$ might be fought with large uncertainties [Matsumoto and Gruber, 2005], although quantifying these uncertainties is difficult. The lower bias of the model inventory for $\mathrm{C}_{\mathrm{ant}}$ in the deep ocean appears in marked contrast to the fact that our model reproduces observations of the Labrador Sea Water inventory of CFC-11 quite well [Böning et al., 2003]. A similarly large underestimation of $C_{a n t}$ inventory with respect to data-based estimates has also been found in another global model simulation (see the IPSL simulation discussed by $\mathrm{Orr}$ et al. [2001]) of $\mathrm{C}_{\text {ant }}$ that uses the perturbation approach by Siegenthaler and Joos [1992].

[55] The formation of subtropical mode waters is another important pathway for the sequestration of $\mathrm{C}_{\text {ant }}$ [Follows et al., 2002]. Representing their formation and structure correctly requires even higher model resolutions, which would make longer global carbon model studies computationally expensive. Interestingly however, in our study the volume of subtropical and subpolar modewaters differs quite substantially between the eddy-permitting and the coarse-resolution model versions. Nevertheless, this still results in similar total inventories of $\mathrm{C}_{\text {ant }}$ in both the model versions. The misrepresentation of one water mass in the coarse resolution model is compensated by a shift in the $\mathrm{C}_{\mathrm{ant}}$ distribution over density classes. However, if one is interested in changes of the ocean circulation and its effect on the $\mathrm{C}_{\mathrm{ant}}$ sequestration an explicit and correct representation of the individual water masses is essential. The better representation of the upper layer current structure, for example, of the energetic western boundary currents and its branches of the North Atlantic Current in the eddypermitting simulation offers some new perspectives on the relevant mechanisms of the $\mathrm{C}_{\text {ant }}$ uptake.

[56] The gross spatial pattern and magnitudes of the airsea flux of $\mathrm{C}_{\mathrm{ant}}$ in the eddy-permitting model are similar to the coarse-resolution model runs, and consistent with the results from an ensemble of global carbon model integra- 
tions [Orr et al., 2001]. All simulations show maximum rates of uptake in the North Atlantic subpolar gyre, where deep convection brings old water poor in $\mathrm{C}_{\mathrm{ant}}$ to the surface. However, in the eddy-permitting model, the association between the relatively localized convection events and airsea flux is much weaker for $\mathrm{C}_{\mathrm{ant}}$ than for CFC-11. The $\mathrm{C}_{\mathrm{ant}}$ uptake does not only extend over a much larger area in the eastern portion of the gyre, but also shows a clear association to the structure of the North Atlantic surface currents in the model.

[57] A novel Lagrangian analysis [after Follows and Williams, 2004] of the driving forces behind the $\mathrm{C}_{\text {ant }}$ airsea flux is able to separate the role of vertical mixing, heating or cooling, and the temporal evolution of $p \mathrm{CO}_{2}$ on the flux. It shows that vertical mixing contributes most to the air-sea flux over the central subpolar gyre but that there is also a dominant contribution from cooling over the southern portion of the gyre: the latter mechanism contributes to the bulk of the uptake of $\mathrm{C}_{\mathrm{ant}}$ along the path of the North Atlantic Current. While the contribution by vertical mixing is highest in the regions of deep convection in the Labrador and Irminger Seas, it is also significant over parts of the subtropical North Atlantic, associated with the seasonal cycle of the mixed layer deepening. Although in the annual mean, the heat flux over large parts of the midlatitude North Atlantic is directed into the ocean, the effect on $\mathrm{C}_{\mathrm{ant}}$ fluxes is confounded by the temporal correlation between heat fluxes and mixed layer depth, leading to a net forcing of ocean uptake in spite of a net cooling. Finally, the continuing increase of $p \mathrm{CO}_{2}$ is contributing little to the forcing of air-sea flux of $\mathrm{C}_{\text {ant }}$ within most of the subpolar ocean. It is dominant only in the tropical ocean outside a band around the equatorial upwelling.

[58] Like the meridional heat transport, the transport of $\mathrm{C}_{\text {ant }}$ by the ocean is directed northward throughout the subtropical North Atlantic and strongly correlated to variations in the overturning component of the oceanic circulation. Unlike heat transport, however, some correlation with the overturning continues to hold over parts of the subpolar regime, where heat transport if dominated by the gyre part of the circulation. The correlation holds over a large range of timescales from monthly over interannual, and perhaps even in the mean. The reason for the strong coupling of the $\mathrm{C}_{\mathrm{ant}}$ transport to the overturning is the large concentration difference between northward flow of surface waters that carry the imprint of the current $p \mathrm{CO}_{2}$ and southward flow of older waters that have not been in contact with the atmosphere recently. This contrast is acerbated by the fact that $\mathrm{C}_{\text {ant }}$ values tend to be higher in warmer waters than in colder, because of differences in the buffer factor. A further implication of the correlation between the transports of heat and $\mathrm{C}_{\mathrm{ant}}$ is that coarse-resolution models, which tend to have a too sluggish overturning, and may underestimate the northward transport of $\mathrm{C}_{\mathrm{ant}}$ in the North Atlantic, and therefore perhaps overestimate the effect of the local airsea flux [Wallace, 2001].

[59] The strong coupling between overturning and $\mathrm{C}_{\mathrm{ant}}$ transport implies that a reduction of the intensity of the Atlantic overturning by about $30 \%$ during the 21 st century as prognosticated by climate models [Gregory et al., 2005] should lead to a significant decrease in $\mathrm{C}_{\mathrm{ant}}$ transport. One might speculate, however, whether such a reduction in transport might lead to enhanced or reduced air-sea flux of $\mathrm{C}_{\text {ant }}$ north of that latitude. It would be interesting to know whether such a purely physical mechanism might be behind the inferred reduction in air-sea flux of $\mathrm{C}_{\text {ant }}$ in recent studies by Omar et al. [2003], Lefèvre et al. [2004] and Omar and Olsen [2006]. However, because of the setup of our model (i.e., the perturbation approach for $\mathrm{C}_{\mathrm{ant}}$ ), we are not able to discuss the potentially large feedbacks between variability in the physical circulation and the biological carbon pump [e.g., Follows and Dutkiewicz, 2002] and their repercussions on the uptake of $\mathrm{C}_{\mathrm{ant}}$.

[60] Acknowledgments. We gratefully acknowledge the work of Jens-Olaf Beismann, Lars Czeschel and Julia Getzlaff of IFM-GEOMAR in setting up and also carrying out main parts of the model runs. Rene Redler, C\&C Research Laboratories, NEC Europe, has postprocessed the CFC-11 fluxes. The integration of the coarse-resolution model has been performed at the computing center of Kiel University, those of the eddypermitting model at the Höchstleistungsrechenzentrum Stuttgart and the Deutsches Klimarechenzentrum Hamburg. We wish to acknowledge use of the Ferret program for analysis and graphics in this paper. Ferret is a product of NOAA's Pacific Marine Environmental Laboratory. (Information is available at www.ferret.noaa.gov). The analysis was performed under the BMBF project DEKLIM (contract 01 LD 0102).

\section{References}

Anderson, L. G., M. Chierici, E. Fogelqvist, and T. Johannessen (2000), Flux of anthropogenic carbon into the deep Greenland Sea, J. Geophys. Res., 105(C6), 14,339-14,345.

Archambeau, A.-S., C. Pierre, A. Poisson, and B. Schauer (1998), Distributions of oxygen and cabon stable isotopes and CFC-12 in the water masses of the Southern Ocean at 30 E from South Africa to Antarctica: Results of the CIVA1 cruise, J. Mar. Syst., 17, 25-38.

Barnier, B., L. Siefried, and P. Marchesiello (1995), Thermal forcing for a global ocean circulation model using a three-year climatology of ECMWF analyses, J. Mar. Syst., 6, 363-380.

Beckmann, A., and R. Döscher (1997), A method for improved representation of dense water spreading over topography in geopotential-coordinate models, J. Phys. Oceanogr., 27, 581-591.

Beismann, J.-O., and R. Redler (2003), Model simulations of CFC uptake in the Atlantic Ocean: Effects of parameterizations and grid resolution, J. Geophys. Res., 108(C5), 3159, doi:10.1029/2001JC001253.

Beismann, J.-O., C. W. Böning, and D. Stammer (2002), Inter-annual to decadal variability of the meridional overturning circulation of the Atlantic: A comparison of the response to atmospheric fluctuations in three ocean models, CLIVAR Exchanges, 25, 34-46.

Böning, C. W., M. Rhein, J. Dengg, and C. Dorow (2003), Modeling CFC inventories and formation rates of Labrador Sea Water, Geophys. Res. Lett., 30(2), 1050, doi:10.1029/2002GL014855.

Boyer, T. P., and S. Levitus (1997), Objective Analysis of Temperature and Salinity for the World Ocean on a $1 / 4^{\circ}$ Grid, NOAA Atlas NESDIS, vol. 11, NOAA, Silver Spring, Md.

Broecker, W., J. Ledwell, T. Takahashi, R. Weiss, L. Merlivat, L. Memery, T.-H. Peng, B. Jahne, and K. Munnich (1986), Isotopic versus micrometeorologic ocean $\mathrm{CO}_{2}$ fluxes: A serious conflict, J. Geophys. Res., 91(C9), 10,517-10,527.

Caldeira, K., and P. Duffy (2000), The role of the Southern Ocean in uptake and storage of anthropogenic carbon dioxide, Science, 287, 620-622.

Doney, S. C., et al. (2004), Evaluating global ocean carbon models: The importance of realistic physics, Global Biogeochem. Cycles, 18, GB3017, doi:10.1029/2003GB002150.

Dutay, J.-C., et al. (2002), Evaluation of ocean model ventilation with CFC11: Comparison of 13 global ocean models, Ocean Modell., 4, 89-120.

Eden, C., and J. Willebrand (2001), Mechanism of interannual to decadal variability of the North Atlantic circulation, J. Clim., 14, 2266-2280.

England, M., V. Garçon, and J.-F. Minster (1994), Chlorofluorocarbon uptake in a world ocean model: 1 . Sensitivity to the surface gas forcing, J. Geophys. Res., 99(C12), 25,215-25,233.

Enting, I. G., T. M. L. Wigley, and M. Heimann (1994), Future emissions and concentrations of carbon dioxide: Key ocean/atmosphere/land analyses, Tech. Rep. 31, 7 pp., Div. of Atmos. Res., CSIRO, Hobart, Tasmania, Australia.

Follows, M., and S. Dutkiewicz (2002), Meteorological modulation of the North Atlantic spring bloom, Deep Sea Res., Part II, 49, 321-344.

Follows, M., and R. Williams (2004), Mechanisms controlling the air-sea flux of $\mathrm{CO}_{2}$ in the North Atlantic, in The Ocean Carbon Cycle and 
Climate, edited by M. Follows and T. Oguz, pp. 217-249, Springer, New York.

Follows, M., T. Ito, and J. Marotzke (2002), The wind-driven, subtropical gyres and the solubility pump of $\mathrm{CO}_{2}$, Global Biogeochem. Cycles, 16(4), 1113, doi:10.1029/2001GB001786

Frew, N., et al. (2004), Air-sea gas transfer: Its dependence on wind stress, small-scale roughness, and surface films, J. Geophys. Res., 109, C08S17, doi:10.1029/2003JC002131.

Friedlingstein, P., J.-L. Dufresne, P. Cox, and P. Rayner (2003), How positive is the feedback between climate and the carbon cycle?, Tellus, Ser. $B, 55,692-700$.

Ganachaud, A., and C. Wunsch (2000), Improved estimates of global ocean circulation, heat transport and mixing from hydrographic data, Nature, 408, 453-457.

Gent, P. R., and J. McWilliams (1990), Isopycnal mixing in ocean circulation models, J. Phys. Oceanogr., 20, 150-155.

Getzlaff, J., C. W. Böning, C. Eden, and A. Biastoch (2005), Signal propagation in the North Atlantic overturning, Geophys. Res. Lett., 32, L09602, doi:10.1029/2004GL021002.

Gloor, M., N. Gruber, J. Sarmiento, C. L. Sabine, and R. A. Feely (2003), A first estimate of present and preindustrial air-sea $\mathrm{CO}_{2}$ flux patterns based on ocean interior carbon measurements and models, Geophys. Res. Lett., 30(1), 1010, doi:10.1029/2002GL015594.

Gregory, J. M., et al. (2005), A model intercomparison of changes in the Atlantic thermohaline circulation in response to increasing atmospheric $\mathrm{CO}_{2}$ concentration, Geophys. Res. Lett., 32, L12703, doi:10.1029/ 2005 GL023209.

Griffies, S. M. (1998), The Gent-McWilliams skew flux, J. Phys. Oceanogr., $28,831-841$.

Gruber, N. (1998), Anthropogenic $\mathrm{CO}_{2}$ in the Atlantic Ocean, Global Biogeochem. Cycles, 12, 165-191.

Gruber, N., J. Sarmiento, and T. Stocker (1996), An improved method for detecting anthropogenic $\mathrm{CO}_{2}$ in the oceans, Global Biogeochem. Cycles, $10,809-837$

Hall, T. M., D. W. Waugh, T. W. N. Haine, P. E. Robbins, and S. Khatiwala (2004), Estimates of anthropogenic carbon in the Indian Ocean with allowance for mixing and time-varying air-sea $\mathrm{CO}_{2}$ disequilibrium, Global Biogeochem. Cycles, 18, GB1031, doi:10.1029/2003GB002120.

Han, Y.-J. (1984), A numerical world ocean general circulation model. Part II.: A baroclinic experiment, Dyn. Atmos. Oceans, 8, 141-172.

Haney, R. L. (1971), Surface thermal boundary condition for ocean circulation models, J. Phys. Oceanogr., 1, 241-248.

Hirschi, J., J. Baehr, J. Marotzke, J. Stark, S. Cunningham, and J.-O Beismann (2003), A monitoring design for the Atlantic meridional overturning circulation, Geophys. Res. Lett., 30(7), 1413, doi:10.1029/ 2002 GL016776.

Holfort, J., K. M. Johnson, B. Schneider, G. Siedler, and D. W. R. Wallace (1998), Meridional transport of dissolved inorganic carbon in the South Atlantic, Global Biogeochem. Cycles, 12, 479-499.

Jayne, S. R., and J. Marotzke (2001), The dynamics of ocean heat transport variability, Rev. Geophys., 39, 385-411.

Kalnay, E., et al. (1996), The NCEP/NCAR 40-years reanalysis project, Bull. Am. Meteorol. Soc., 77, 437-471.

Keir, R., G. Rehder, E. Suess, and H. Erlenkeuser (1998), The $\delta^{13}$ C anomaly in the northeastern Atlantic, Global Biogeochem. Cycles, 12, 467-477.

Körtzinger, A., J. C. Mintrop, and L. Duinker (1998), On the penetration of anthropogenic $\mathrm{CO}_{2}$ into the North Atlantic Ocean, J. Geophys. Res. $103(\mathrm{C} 9), 18,681-18,689$.

Körtzinger, A., M. Rhein, and L. Mintrop (1999), Anthropogenic $\mathrm{CO}_{2}$ and CFCs in the North Atlantic Ocean: A comparison of man-made tracers, Geophys. Res. Lett., 26, 2065-2068.

Kraus, E. B., and J. S. Turner (1967), A one-dimensional model of the seasonal thermocline II. The general theory and its consequences, Tellus, $19,98-105$

Lee, K., et al. (2003), An updated anthropogenic $\mathrm{CO}_{2}$ inventory in the Atlantic Ocean, Global Biogeochem. Cycles, 17(4), 1116, doi:10.1029/ $2003 \mathrm{~GB} 002067$

Lefèvre, N., A. J. Watson, A. Olsen, A. F. Ríos, F. F. Pérez, and T. Johannessen (2004), A decrease in the sink for anthropogenic $\mathrm{CO}_{2}$ in the North Atlantic, Geophys. Res. Lett., 31, L07306, doi:10.1029/2003GL018957.

Lo Monaco, C., C. Goyet, N. Metzl, A. Poisson, and F. Touratier (2005a), Distribution and inventory of anthropogenic $\mathrm{CO}_{2}$ in the Southern Ocean Comparison of three data-based methods, J. Geophys. Res., 110, C09S02, doi:10.1029/2004JC002571.

Lo Monaco, C., N. Metzl, A. Poisson, C. Brunet, and B. Schauer (2005b), Anthropogenic $\mathrm{CO}_{2}$ in the Southern Ocean: Distribution and inventory at the Indian-Atlantic boundary (World Ocean Circulation Experiment line I6), J. Geophys. Res., 110, C06010, doi:10.1029/2004JC002643.

MacDonald, A. M., and C. Wunsch (1996), An estimate of global ocean circulation and heat fluxes, Nature, 382, 436-439.
MacDonald, A. M., O. O’Neil Baringer, R. Wanninkhof, K. Lee, and D. Wallace (2003), A 1998-1992 comparison of inorganic carbon and its transport across $24.5^{\circ}$ in the Atlantic, Deep Sea Res., Part II, 50, $3041-$ 3064.

Marshall, J., A. Nurser, and R. Williams (1993), Inferring the subduction rate and period over the North Atlantic, J. Phys. Oceanogr., 23, $1315-$ 1329

Matsumoto, K., and N. Gruber (2005), How accurate is the estimation of anthropogenic carbon in the ocean? An evaluation of the $\Delta C^{*}$ method, Global Biogeochem. Cycles, 19, GB3014, doi:10.1029/2004GB002397.

Matsumoto, K., et al. (2004), Evaluation of ocean carbon cycle models with data-based metrics, Geophys. Res. Lett., 31, L07303, doi:10.1029/ 2003GL018970.

McGillis, W., and R. Wanninkhof (2006), Aqueous CO2 gradients for airsea flux estimates, Mar. Chem., 98, 100-108.

McGillis, W. R., J. W. H. Dacey, N. M. Frew, E. J. Bock, and R. K. Nelson (2000), Water-air flux of dimethylsulfide, J. Geophys. Res, 105(C1), $1187-1193$.

Mikaloff Fletcher, S., et al. (2006), Inverse estimates of anthropogenic $\mathrm{CO}_{2}$ uptake and transport, and storage by the ocean, Global Biogeochem. Cycles, 20, GB2002, doi:10.1029/2005GB002530.

Omar, A. M., and A. Olsen (2006), Reconstructing the time history of the air-sea $\mathrm{CO}_{2}$ disequilibrium and its rate of change in the eastern subpolar North Atlantic, 1972-1989, Geophys. Res. Lett., 33, L04602, doi:10.1029/2005GL025425.

Omar, A., T. Johannessen, S. Kaltin, and A. Olsen (2003), Anthropogenic increase of oceanic $p \mathrm{CO}_{2}$ in the Barents Sea surface water, J. Geophys. Res., 108(C12), 3388, doi:10.1029/2002JC001628.

Orr, J. C., et al. (2001), Estimates of anthropogenic carbon uptake from four three-dimensional global ocean models, Global Biogeochem. Cycles, 15 43-60.

Pacanowski, R. C. (1996), MOM 2 version 2: Documentation, user's guide and reference manual, Tech. Rep. 3.2, 328 pp., Geophys. Fluid Dyn. Lab., Princeton, N. J.

Roether, W., R. Schlitzer, A. Putzka, P. Beining, K. Bulsiewicz, G. Rohardt, and F. Delahoyde (1993), A chlorofluoromethane and hydrographic sections across Drake Passage: Deep water ventilation and meridional property transport, J. Geophys. Res., 98(C8), 14,423-14,435.

Roson, G., A. F. Rios, F. F. Perez, A. Lavin, and H. L. Bryden (2003), Carbon distribution, fluxes, and budgets in the subtropical North Atlantic Ocean $\left(24.5^{\circ} \mathrm{N}\right)$, J. Geophys. Res., 108(C5), 3144, doi:10.1029/ 1999JC000047.

Sabine, C. L., R. M. Key, K. M. Johnson, F. J. Millero, A. Poisson, J. L. Sarmiento, D. W. R. Wallace, and C. D. Winn (1999), Anthropogenic $\mathrm{CO}_{2}$ inventory of the Indian Ocean, Global Biogeochem. Cycles, 13, $179-198$.

Sabine, C. L., et al. (2004), The oceanic sink for anthopogenic $\mathrm{CO}_{2}$, Science, 305, 367-371.

Sarmiento, J. L., and N. Gruber (2002), Sinks for anthropogenic carbon, Phys. Today, 55, 30-36.

Sarmiento, J. L., J. C. Orr, and U. Siegenthaler (1992), A perturbation simulation of $\mathrm{CO}_{2}$ uptake in an ocean general circulation model, J. Geophys. Res., 97(C3), 3621-3645.

Siegenthaler, U., and F. Joos (1992), Use of a simple model for studying oceanic tracer distributions and the global carbon cycle, Tellus, Ser. B, 44 $186-207$.

Takahashi, T., et al. (2002), Global sea-air $\mathrm{CO}_{2}$ flux based on climatological surface ocean $p \mathrm{CO}_{2}$, and seasonal biological and temperature effects, Deep Sea Res., Part II, 49, 1601-1622.

Talley, L. D. (2003), Shallow, intermediate, and deep overturning components of the global heat budget, J. Phys. Oceanogr., 33, 530-560.

Tanhua, T., A. Biastoch, A. Körtzinger, H. Lüger, C. W. Böning, and D. W. Wallace (2006), Changes of anthropogenic $\mathrm{CO}_{2}$ and CFCs in the North Atlantic between 1981 and 2004, Global Biogeochem. Cycles, 20, GB4017, doi:10.1029/2006GB002695.

Volk, T., and M. Hoffert (1985), Ocean carbon pumps: Analysis of relative strengths and efficiencies in ocean-driven atmospheric $\mathrm{CO}_{2}$ changes, in The Carbon Cycle and Atmospheric $\mathrm{CO}_{2}$ : Natural Variations Archean to Present, Geophys. Monogr. Ser., vol. 32, edited by E. T. Sundquist and W. S. Broecker, pp. 99-110, AGU, Washington, D. C.

Völker, C., D. W. R. Wallace, and D. A. Wolf-Gladrow (2002), On the role of heat fluxes in the uptake of anthropogenic carbon in the North Atlantic, Global Biogeochem. Cycles, 16(4), 1138, doi:10.1029/2002GB001897.

Wallace, D. (2001), Storage and transport of excess $\mathrm{CO}_{2}$ in the oceans: The JGOFS/WOCE global $\mathrm{CO}_{2}$ survey, in Ocean Circulation and Climate: Observing and Modelling the Global Ocean, edited by J. Siedler, J. Church, and J. Gould, pp. 489-521, Academic Press, San Diego, Calif. Wanninkhof, R. (1992), Relationship between wind speed and gas exchange over the ocean, J. Geophys. Res., 97(C5), 7373-7382. 
Wanninkhof, R., and W. R. McGillis (1999), A cubic relationship between air-sea CO2 exchange and wind speed, Geophys. Res. Lett., 26, 18891892.

Waugh, D. W., T. M. Hall, and T. W. N. Haine (2004), Transport times and anthropogenic carbon in the subpolar North Atlantic Ocean, Deep Sea Res., Part I, 51, doi:10.1016/j.dsr.2004.06.011.

Woolf, D. (1997), Bubbles and their role in gas exchange, in The Sea Surface and Global Change, edited by P. Liss and R. Duce, pp. 173205, Cambridge Univ. Press, New York.
Woolf, D. (2005), Parameterization of gas transfer velocities and sea-statedependent wave breaking, Tellus, Ser. B, 57, 87-94.

Zappa, C., W. Asher, and A. Jessup (2001), Microscale wave breaking and air-water gas transfer, J. Geophys. Res., 106(C5), 9385-9391.

A. Biastoch and C. W. Böning, Leibniz-Institut für Meereswissenschaften, Düsternbrooker Weg 20, D-24105 Kiel, Germany. (abiastoch@ifmgeomar.de)

C. Völker, Alfred-Wegener-Institut, D-27570 Bremerhaven, Germany. 